Atmos. Chem. Phys. Discuss., 11, 6221-6258, 2011

www.atmos-chem-phys-discuss.net/11/6221/2011/

doi:10.5194/acpd-11-6221-2011

(C) Author(s) 2011. CC Attribution 3.0 License.

\title{
Optical properties of elemental carbon and water-soluble organic carbon in Beijing, China
}

Y. Cheng ${ }^{1}$, K.-B. He ${ }^{1}$, M. Zheng ${ }^{2}$, F.-K. Duan ${ }^{1}$, Y.-L. Ma ${ }^{1}$, Z.-Y. Du ${ }^{1}$, J.-H. Tan ${ }^{1}$, J.-M. Liu ${ }^{3}$, X.-L. Zhang ${ }^{3}$, R. J. Weber ${ }^{3}$, M. H. Bergin ${ }^{3,4}$, and A. G. Russell ${ }^{4}$

${ }^{1}$ State Key Joint Laboratory of Environment Simulation and Pollution Control, Department of Environmental Science and Engineering, Tsinghua University, Beijing, China

${ }^{2}$ College of Environmental Sciences and Engineering, Peking University, Beijing, China

${ }^{3}$ School of Earth and Atmospheric Sciences, Georgia Institute of Technology, Atlanta, Georgia, USA

${ }^{4}$ School of Civil and Environmental Engineering, Georgia Institute of Technology, Atlanta, Georgia, USA

Received: 28 January 2011 - Accepted: 15 February 2011 - Published: 22 February 2011 Correspondence to: Y. Cheng (chengyuan02@gmail.com)

Published by Copernicus Publications on behalf of the European Geosciences Union.

Optical properties of elemental carbon and water-soluble organic carbon

Y. Cheng et al.

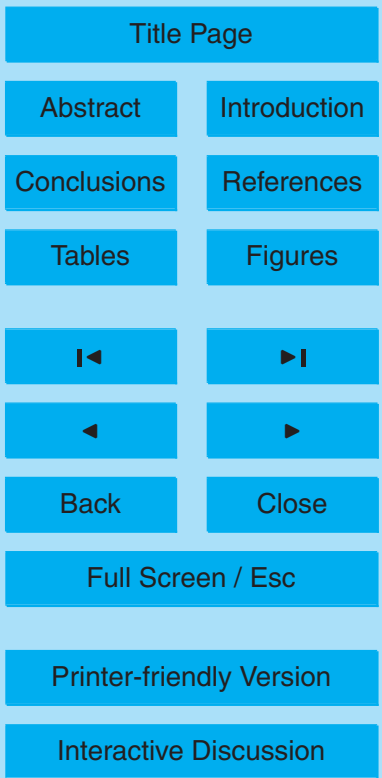




\section{Abstract}

The mass absorption cross-section (MAC) of elemental carbon (EC) in Beijing was quantified using a thermal-optical carbon analyzer and the influences of mixing state and sources of carbonaceous aerosol were investigated. The MAC measured at $5632 \mathrm{~nm}$ was 29.0 and $32.0 \mathrm{~m}^{2} \mathrm{~g}^{-1}$ during winter and summer respectively. MAC correlated well with the organic carbon $(\mathrm{OC})$ to $\mathrm{EC}$ ratio $\left(R^{2}=0.91\right)$ which includes important information about the extent of secondary organic aerosol (SOA) production, indicating the enhancement of MAC by coating with SOA. The extrapolated MAC value was $10.5 \mathrm{~m}^{2} \mathrm{~g}^{-1}$ when the OC to EC ratio is zero, which was $5.6 \mathrm{~m}^{2} \mathrm{~g}^{-1}$ after correction by the enhancement factor (1.87) caused by the artifacts associated with the "filter-based" methods. The MAC also increased with sulphate $\left(R^{2}=0.84\right)$ when the sulphate concentration was below $10 \mu \mathrm{g} \mathrm{m}^{-3}$, whereas MAC and sulphate were only weekly related when the sulphate concentration was above $10 \mu \mathrm{g} \mathrm{m}^{-3}$, indicating the MAC of EC was also enhanced by coating with sulphate. Based on a converting approach that accounts for the discrepancy caused by measurements methods of both light absorption and EC concentration, previously published MAC values were converted to the "equivalent MAC", which is the estimated value if using the same measurement methods as used in this study. The "equivalent MAC" was found to be much lower in the regions heavily impacted by biomass burning (e.g., India), probably due to the influence of brown carbon. Optical properties of water-soluble organic carbon (WSOC) in Beijing were also presented. Light absorption by WSOC exhibited strong wavelength $(\lambda)$ dependence such that absorption varied approximately as $\lambda^{-7}$, which was characteristic of the brown carbon spectra. The mass absorption efficiency $\left(\sigma_{\mathrm{abs}}\right)$ of WSOC (measured at $365 \mathrm{~nm}$ ) was 1.83 and $0.70 \mathrm{~m}^{2} \mathrm{~g}^{-1}$ during winter and summer respectively. 25 The seasonal pattern of $\sigma_{\text {abs }}$ was attributed to the difference in the precursors of SOA, because WSOC in Beijing has been demonstrated to be strongly linked to SOA. Moreover, the $\sigma_{\text {abs }}$ of WSOC in Beijing was much higher than results from the southeastern United States which were obtained using the same method as used in this study, perhaps due to the influence of biomass burning.

Optical properties of elemental carbon and water-soluble organic carbon

Y. Cheng et al.

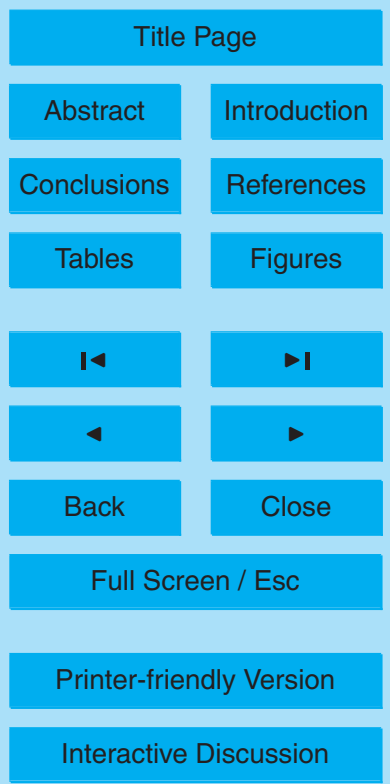




\section{Introduction}

Carbonaceous aerosol has been the focus of extensive studies during the last decade due to its complex effects on human health, visibility and climate change. Carbonaceous aerosol is an aggregate of thousands of poorly characterized species with a 5 wide range of chemical, thermal and optical properties (Pöschl, 2005; Andreae and Gelencsér, 2006). As a result, its characterization is more difficult and complex compared with other components in ambient aerosol (e.g., sulphate and mineral dust). Though it is still impossible to completely identify carbonaceous aerosol on a molecular level, a variety of techniques has been developed to classify it into different fractions result10 ing in several "instrument-operational definitions" which are usually not congruent. In speciation monitoring, carbonaceous aerosol is commonly divided into organic carbon (OC) and elemental carbon (EC) by thermal-optical (or thermal) method (Chow et al., 1993; Birch and Cary, 1996). Another widely used definition is black carbon (BC), which is the light-absorbing carbon measured by optical instruments such as Aethalometer

15 (Hansen and Novakov, 1990). In the emission-inventory and climate-science community, black carbon is usually used synonymously with EC, because the emission factors of $\mathrm{BC}$ are typically measured by thermal-optical (or thermal) methods. Recently, scientific attention has shifted from the role of black carbon as a pollutant to its importance as a driver of global warming (Jacobson, 2001; Ramanathan and Carmichael, 2008).

20 Atmospheric heating caused by black carbon may affect the large scale circulation and the hydrological cycle with significant regional climate effects that contribute to the observed precipitation (increased summer floods in south China, increased drought in north China) and temperature (moderate cooling in China while most of the world has been warming) changes in China (Ramanathan et al., 2001; Menon et al., 2002).

25 The mass absorption cross-section (MAC, $\mathrm{m}^{2} \mathrm{~g}^{-1}$ ), a parameter characterizing the optical properties of black carbon, is defined as:

$\operatorname{MAC}\left(\mathrm{m}^{2} \mathrm{~g}^{-1}\right)=\frac{b_{\mathrm{abs}}}{\mathrm{BC}}$

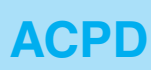

$11,6221-6258,2011$

Optical properties of elemental carbon and water-soluble organic carbon

Y. Cheng et al.

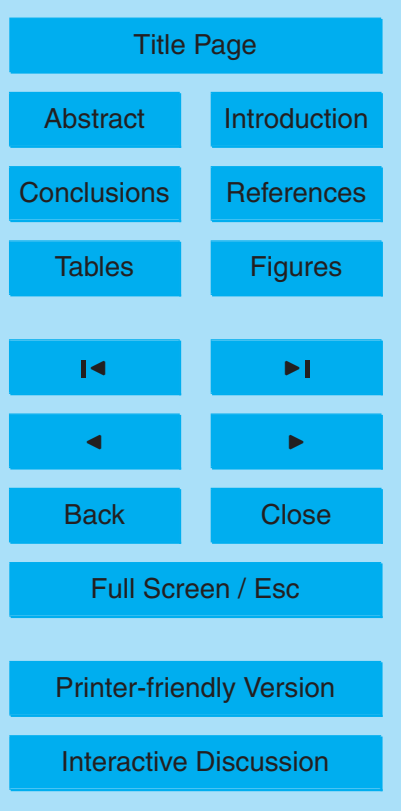


where $b_{\mathrm{abs}}$ and $\mathrm{BC}$ is the absorption coefficient $\left(\mathrm{Mm}^{-1}\right)$ and mass concentration of

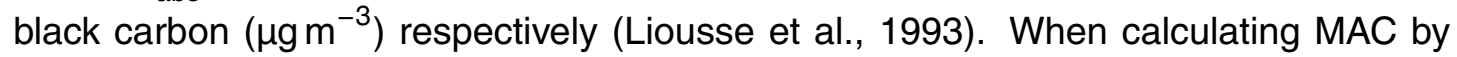
Eq. (1), EC measured by thermal-optical (or thermal) method is typically used as BC, and absorption measurements have most frequently been performed by "filter-based" 5 techniques (e.g., Aethalometer) which measure the change in the light transmittance through a filter due to the deposition of airborne particles (Sharma et al., 2002; Jeong et al., 2004; Snyder and Schauer, 2007; Knox et al., 2009). However, significant artifacts are associated with the "filter-based" method, due to the aerosol-filter interactions, shadowing of the incident light with increasing filter loading, and aerosol scattering ef10 fects (Arnott et al., 2003; Weingartner et al., 2003; Petzold et al., 2005; Sandradewi et al., 2008). For example, results from downtown Toronto showed that the MAC value calculated based on Aethalometer was about 2.4 times the value based on photoacoustic spectrometer which can measure light absorption directly on airborne particles (Knox et al., 2009). Another concern in the determination of MAC is the influence of mixing 15 state (Schnaiter et al., 2003, 2005; Bond et al., 2006). When BC is internally mixed with other components such as sulphate and organic carbon, the coatings can focus light into the BC core of the particle which would increase the MAC value (Bergstrom et al., 1982). Enhancement of MAC by coating can be described by absorption amplification. Laboratory studies showed that the amplification factor was $1.8 \sim 2.1$ for diesel 20 soot particles when coated with secondary organic carbon produced by the oxidation of $\alpha$-pinene (Schnaiter et al., 2005). The effects of coatings can also be evaluated by using a thermal-denuder which volatilizes the coatings (or a fraction of the coatings) by heating the airborne aerosol before absorption measurement. For example, Knox et al. (2009) found that the MAC of freshly emitted BC, which was calculated based on 25 Aethalometer at $880 \mathrm{~nm}$, was reduced by about $25 \%$ (from 19.3 to $14.4 \mathrm{~m}^{2} \mathrm{~g}^{-1}$ ) after heating.

Black carbon is typically treated as the only light-absorbing species in climate models (Kirchstetter et al., 2004). However, it has been recently made clear that certain organic carbon species in addition to black carbon may also contribute to light absorption by

Optical properties of elemental carbon and water-soluble organic carbon

Y. Cheng et al.

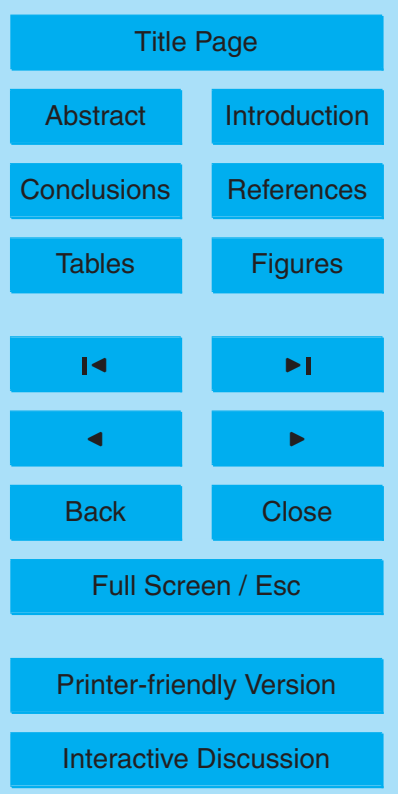


atmospheric aerosols, indicating a continuum of carbonaceous components (Pöschl, 2005; Andreae and Gelencsér, 2006). Light absorbing organic aerosol is usually termed brown carbon. Sources of brown carbon include residential coal combustion (Bond, 2001), biomass burning (Kirchstetter et al., 2004; Clarke et al., 2007; Bergstrom 5 et al., 2007; Zhang et al., 2010), biogenic materials (Andreae and Crutzen, 1997), and atmospheric reactions (Gelencsér et al., 2003; Hecobian et al., 2010). Laboratory studies also provide additional evidence for the presence of brown carbon (Schnaiter et al., 2006; Chakrabarty et al., 2006, 2010). The "tar balls", which have been widely observed in Africa, Europe (Pósfai et al., 2004), North America (Hand et al., 2005) 10 and Asia (Alexander et al., 2008), are considered as an important type of brown carbon. Though both can absorb light, "tar balls" differs substantially from black carbon in terms of morphology. "Tar balls" are large, amorphous, and predominantly isolated carbon spheres with diameter of 100 to $400 \mathrm{~nm}$ (Alexander et al., 2008), whereas black carbon typically consists of aggregates of spherules mostly 20 to $50 \mathrm{~nm}$ in diameter 15 (van Poppel et al., 2005). The mass absorption efficiency of brown carbon increases sharply from long to short wavelengths, resulting in its brown appearance (Alexander et al., 2008). Absorption of ultraviolet (UV) light by brown carbon is important since UV irradiance significantly affects the tropospheric ozone production and photochemistry (Jacobson, 1999). Moreover, a significant fraction of brown carbon is water-soluble 20 (Hoffer et al., 2006). Dissolution of brown carbon into cloud droplets could result in homogeneous absorbing droplets that affect the overall cloud absorption, especially in the UV range, indicating that brown carbon might have important influence on climate (Andreae and Gelencsér, 2006).

The radiative forcing of carbonaceous aerosol is one of the difficult challenges in 25 climate modeling. Substantial uncertainties are due to the complexity in optical parameters of $\mathrm{EC}$ in the real atmosphere and the presence of light-absorbing organic carbon which is still poorly understood. In this study, optical properties of carbonaceous aerosol in Beijing, a representative mega city in East Asia, are presented. The $\mathrm{MAC}$ of EC is quantified using a thermal-optical carbon analyzer. Influence of source

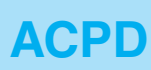

$11,6221-6258,2011$

Optical properties of elemental carbon and water-soluble organic carbon

Y. Cheng et al.

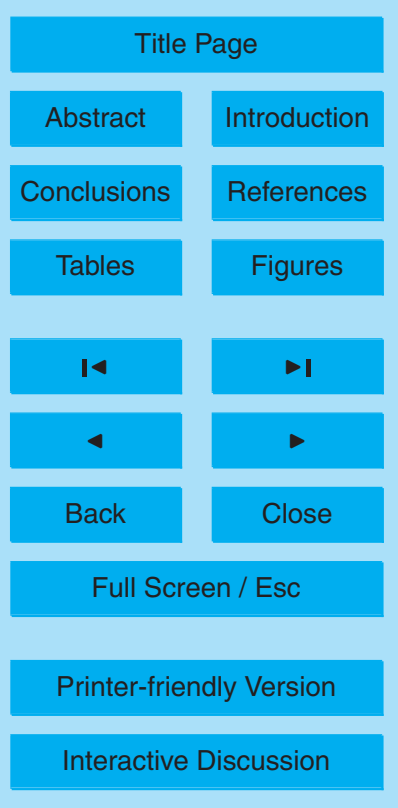


and mixing state on the measured MAC values are investigated based on a converting approach that accounts for the discrepancy caused by the measurement methods of both light absorption and EC concentration. Moreover, light absorption characteristics of the $\mathrm{PM}_{2.5}$ water extracts are also presented.

\section{Methods}

\subsection{Field sampling}

Ambient $\mathrm{PM}_{2.5}$ samples were collected by a five-channel Spiral Ambient Speciation Sampler (SASS, MetOne Inc.) at the Tsinghua University campus in Beijing. Twentynine and thirty sets of daily $\mathrm{PM}_{2.5}$ samples were collected during winter and summer, 10 respectively, in 2009. Parallel quartz filters (denuded) and Teflon filters (un-denuded) were used in the present study. Detailed operating configuration of the SASS sampler during each sampling period was described by Cheng et al. (2010). The activated carbon denuder (provided by MetOne) is $20 \mathrm{~mm}$ long and $38 \mathrm{~mm}$ in diameter with about 1000 of $1 \mathrm{~mm} \times 1 \mathrm{~mm}$ channels. A new denuder was used for each sampling campaign. Cheng et al. (2010) demonstrated that the denuder efficiency for removing the positive artifact was $100 \%$ throughout each sampling period. Particle loss due to diffusion to the walls of the denuder, volatilization of particulate organic carbon during transportation through the denuder, and the shedding of the denuder material were also shown to be negligible.

20 The quartz (2500 QAT-UP) and Teflon (R2PJ047) filters were from Pall Corp. (Ann Arbor, MI), and were $47 \mathrm{~mm}$ in diameter. The face velocity was $9.8 \mathrm{~cm} \mathrm{~s}^{-1}$ at the operating flow rate $\left(6.7 \mathrm{~L} \mathrm{~min}^{-1}\right)$. All of the quartz and Teflon filters used throughout each campaign were taken from the same lot. The quartz filters were pre-baked at $550^{\circ}$ in air for $24 \mathrm{~h}$, whereas the Teflon filters were used as received from the manufacturer.

25 Twenty-nine quartz filters were kept as filter blanks. The OC concentrations of the blank filters averaged $0.44 \pm 0.15 \mu \mathrm{gC} \mathrm{cm}^{-2}$, and no $\mathrm{EC}$ was detected. All of the data reported have been corrected by the filter blank concentration.

\section{ACPD}

$11,6221-6258,2011$

Optical properties of elemental carbon and water-soluble organic carbon

Y. Cheng et al.

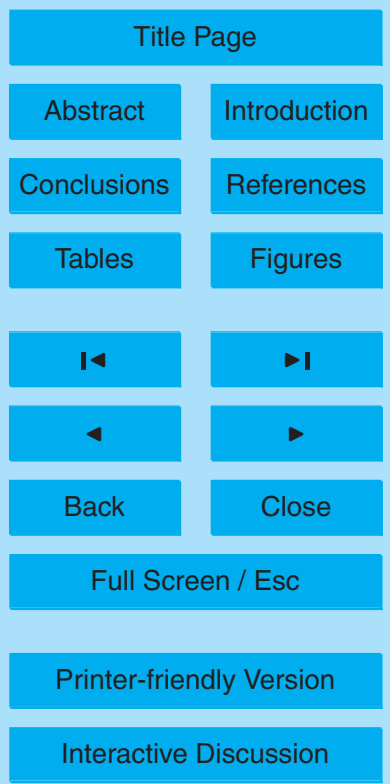




\subsection{Sample analysis}

\subsubsection{Thermal-optical analysis}

Quartz filters were analyzed using a DRI Model 2001 thermal/optical carbon analyzer (Atmoslytic Inc., Calabasas, CA) to determine the EC concentration and optical atten5 uation. The IMPROVE-A temperature protocol was implemented and EC was defined as the carbon evolved after the filter transmittance (monitored at $632, \mathrm{~nm}$ ) returned to its initial value in the oxidizing atmosphere $\left(\mathrm{He} / \mathrm{O}_{2}\right)$. The light attenuation caused by the presence of EC is defined as:

$\operatorname{ATN}=\ln \left(\frac{I_{0}}{l}\right)$

10 where $I$ and $I_{0}$ are the transmittance signal before and after the thermal-optical analysis. The determination of ATN is similar to that used in the Aethalometer, which simultaneously measures light passing through a loaded and a particle-free reference quartz filter. The absorption coefficient of the loaded aerosol $\left(b_{\mathrm{abs}}\right)$ is calculated as:

$b_{\text {abs }}\left(\mathrm{Mm}^{-1}\right)=\mathrm{ATN} \times \frac{A}{V}$

15 where $A$ is the filter area with particle loading $\left(\mathrm{mm}^{2}\right)$ and $V$ is the volume of air sampled $\left(\mathrm{m}^{3}\right)$. MAC is calculated as:

$\operatorname{MAC}\left(\mathrm{m}^{2} \mathrm{~g}^{-1}\right)=\frac{b_{\mathrm{abs}}}{\mathrm{EC}}=\frac{\mathrm{ATN} \times A}{\mathrm{EC} \times V}=\frac{\mathrm{ATN}}{\mathrm{EC}_{s}} \times 10^{2}$

where $\mathrm{EC}_{s}\left(\mu \mathrm{gC} \mathrm{cm}{ }^{-2}\right)$ is the filter loading of $\mathrm{EC}$.

Optical properties of elemental carbon and water-soluble organic carbon

Y. Cheng et al.

Title Page

Abstract

Conclusions

Tables

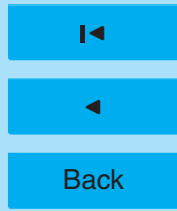

Full Screen / Esc

Printer-friendly Version 


\subsubsection{Water-soluble organic carbon and brown carbon analysis}

Each Teflon filter was placed in a pre-cleaned $60 \mathrm{ml}$ Nalgene amber HDPE bottle and extracted with $40 \mathrm{ml}$ of $18-\mathrm{M} \Omega$ Milli-Q water via $30 \mathrm{~min}$ sonication. The liquid extract was then filtered using a $0.45 \mu \mathrm{m}$ PTFE syringe filter and then stored in a refrigerator

$5 \quad\left(\sim 4^{\circ}\right)$ until analysis, which was completed within 2 days after extraction. Sulphate and water-soluble organic carbon (WSOC) in the extract was quantified using an lon Chromatography (Dionex-600) and a Sievers Model 900 Total Organic Carbon Analyzer (GE Analytical Instruments, Boulder, $\mathrm{CO}$ ) respectively.

The light absorption spectra of the liquid extracts were measured over the wave10 length range of 250 to $800 \mathrm{~nm}$ with a UV-Visible Spectrophotometer and Long-Path Absorption Cell, following the method of Hecobian et al. (2010). Water extracts were injected into a 1-m path-length Liquid Waveguide Capillary Cell (LWCC-2100, World Precision Instrument, Sarasota, FL) with an internal volume of $250 \mu \mathrm{L}$. A dual deuterium and tungsten halogen light source (DT-Mini-2, Ocean Optics, Dunedin, FL) and absorption spectrometer (USB4000, Ocean Optics, Dunedin, FL) were coupled to the wave-guide via fiber optic cables (QP400-2-SR, Ocean Optics, Dunedin, FL). The absorption spectra were recorded with an Ocean Optics Spectra-Suite data acquisition system.

Light absorption of the liquid extracts is defined as:

$20 \quad \operatorname{ATN}_{\lambda}=-\log _{10}\left(\frac{I}{I_{0}}\right)=L \times \sum_{i}\left(C_{i} \times \varepsilon_{i, \lambda}\right)$

where $I_{0}$ and $/$ are the intensity of incident and transmitted light respectively. $\operatorname{ATN}_{\lambda}$ is linearly dependent on the concentration of light-absorbing substances in solution $\left(C_{i}\right)$, their wavelength-dependent mass absorption coefficient $\left(\varepsilon_{i, \lambda}\right)$, and the absorbing path length ( $L)$. ATN ${ }_{\lambda}$ is then converted to an absorption coefficient $\left(b_{\mathrm{abs}}\right)_{\lambda}$ by:

$25 \quad\left(b_{\mathrm{abs}}\right)_{\lambda}=\left(\mathrm{ATN}_{\lambda}-\mathrm{ATN}_{700}\right) \times \frac{V_{\mathrm{W}}}{V \times L} \times \ln (10)$

Optical properties of elemental carbon and water-soluble organic carbon

Y. Cheng et al.

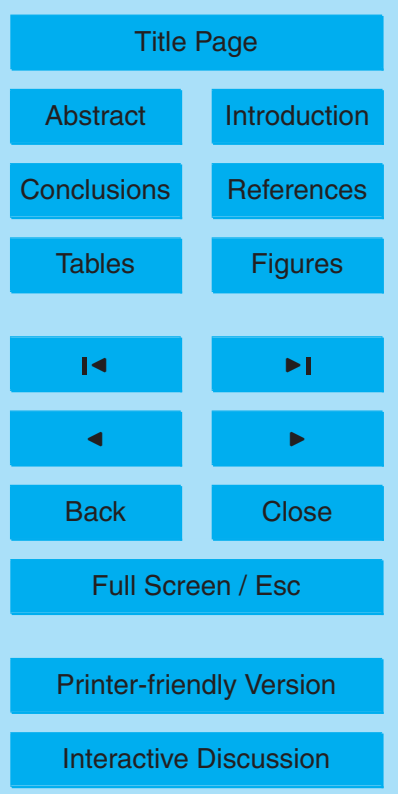


where $V_{W}$ is the volume of water into which the filter was extracted $(40 \mathrm{ml}), V$ is the volume of air sampled, and $L$ is the absorbing path length $(0.94 \mathrm{~m})$. Absorbance at $700 \mathrm{~nm}$ (average between 695 and $705 \mathrm{~nm}$, where there is no absorption for ambient aerosol water extracts) is used to account for baseline drift during analysis. Ln (10) 5 converts from common logarithm (base 10) to natural logarithm. The mass absorption efficiency $\left(\sigma_{\mathrm{abs}}\right)_{\lambda}$ of the water extracts is calculated as:

$\left(\sigma_{\mathrm{abs}}\right)_{\lambda}=\frac{\left(b_{\mathrm{abs}}\right)_{\lambda}}{\mathrm{WSOC}}$

\section{Results and Discussion}

\subsection{Optical properties of elemental carbon}

10 The dependence of light attenuation measured at $632 \mathrm{~nm}(\mathrm{ATN})$ on $\mathrm{EC}$ loading $\left(\mathrm{EC}_{s}\right.$, $\left.\mu \mathrm{gC} \mathrm{cm}{ }^{-2}\right)$ is shown in Fig. 1. During the winter, ATN and $\mathrm{EC}_{s}$ correlated well $\left(R^{2}=\right.$ $0.915)$ with a slope of $29.0 \mathrm{~m}^{2} \mathrm{~g}^{-1}$ and an intercept of $5.7 \mathrm{~m}^{2} \mathrm{~g}^{-1}$ when the $\mathrm{EC}_{s}$ was below $7 \mu \mathrm{gC} \mathrm{cm}^{-2}$, whereas the linearity did not extend for $\mathrm{EC}_{s}$ exceeding $7 \mu \mathrm{gC} \mathrm{cm}{ }^{-2}$ due to the shadowing effect. During the summer, $\mathrm{EC}_{s}$ was much lower (below $4 \mu \mathrm{gC} \mathrm{cm}^{-2}$ ) 15 and ATN was less variable; regression between ATN and $\mathrm{EC}_{s}$ showed a slope of $32.0 \mathrm{~m}^{2} \mathrm{~g}^{-1}$ and an intercept of $4.8 \mathrm{~m}^{2} \mathrm{~g}^{-1}\left(R^{2}=0.604\right)$. The relatively low intercept values obtained in this study indicated that EC was the major light-absorbing component of $\mathrm{PM}_{2.5}$ in Beijing.

\subsection{Effects of the measurement methods}

20 Previous studies have quantified the MAC by the "filter-based" method at a variety of locations (Table 1). However, quite different measurement methods of both ATN and $\mathrm{EC}_{s}$ have been implemented, introducing complexity and difficulty in the direct comparison of MAC across studies and regions. As a result, an approach was developed

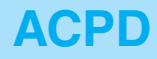

11, 6221-6258, 2011

Optical properties of elemental carbon and water-soluble organic carbon

Y. Cheng et al.

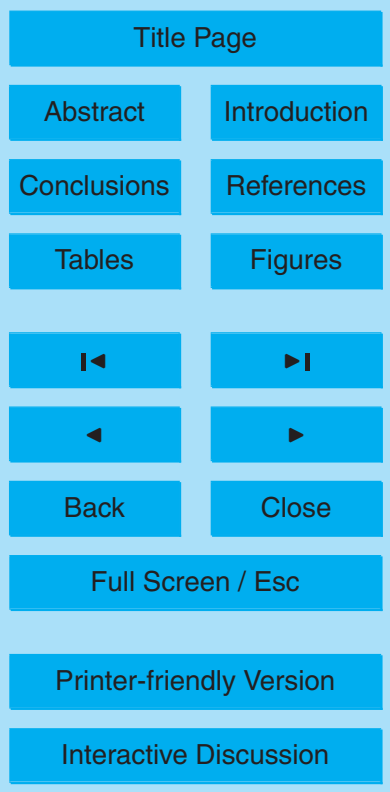

Interactive Discussion 
to account for the discrepancy caused by measurements methods of both ATN and $\mathrm{EC}_{s}$. Based on this approach, previously reported MAC values were converted to the "equivalent MAC", which is the estimated value if using the same measurement methods (of both ATN and $\mathrm{EC}_{s}$ ) as used in this study. This was done using the following 5 procedures.

(1) EC method conversion. The thermal-optical method is widely used for the determination of EC. A variety of operational protocols have been employed that differ mainly with respect to (i) temperature protocol, including temperature plateaus and residence time at each plateaus, and (ii) charring correction by light reflectance or transmittance. 10 EC values defined by transmittance correction $\left(E_{\mathrm{T}}\right)$ are usually lower than those defined by reflectance correction $\left(E C_{R}\right)$, because the filter reflectance signal typically returns to its initial value before the transmittance (Chow et al., 2004). Influence of the charring correction methods on EC values is shown in Table 2. When using the IMPROVE or the IMPROVE-A temperature protocol, the $\mathrm{EC}_{\mathrm{R}}$ to $\mathrm{EC}_{\mathrm{T}}$ ratio was about $151.3 \sim 1.8$ for ambient samples whereas the ratio was a little lower (about 1.2) for motor vehicle exhaust samples. As a result, when converting MAC values in which EC was determined by the IMPROVE (or IMPROVE-A) temperature protocol with reflectance correction, the reported MAC was multiplied by $1.3 \sim 1.8$ to account for the discrepancy caused by charring correction methods. On the other hand, the $\mathrm{EC}_{\mathrm{R}}$ to $\mathrm{EC}_{\mathrm{T}}$ ratio varied 20 significantly (by a factor of more than 3 ) when the NIOSH or similar temperature protocol (STN) was used (Table 2), perhaps due to the influence of "early split" which means the reflectance or transmittance signal returns to its initial value before the introduction of $\mathrm{O}_{2}$. "Early split" is usually caused by the high peak inert mode temperature (e.g., $870^{\circ}$ and $900^{\circ}$ used in NIOSH and STN protocol) which might result in the premature evolution of light-absorbing carbon (Sciare et al., 2003; Subramanian et al., 2006; Cheng et al., 2010). "Early split" occurs more frequently for the reflectance signal. For example, it happens in about $80 \%$ and $40 \%$ of the Fresno samples when using the reflectance and transmittance correction respectively (the temperature protocol was STN); and the $E_{C_{R}}$ to $E C_{T}$ ratio was as high as about 3.5 (Chow et al., 2004). In case

\section{Optical properties of} elemental carbon and water-soluble organic carbon

Y. Cheng et al.

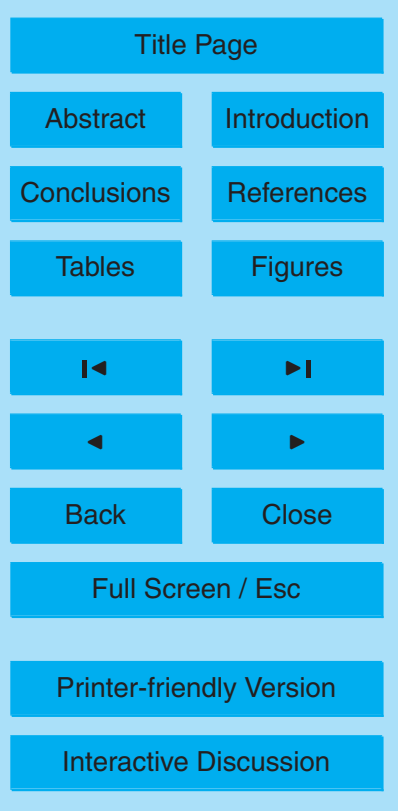


of "early split", all of the carbon involved in the $\mathrm{He} / \mathrm{O}_{2}$ mode would be classified as EC. If "early split" occurs for both the reflectance and transmittance signal, $\mathrm{EC}_{\mathrm{R}}$ would be the same as $\mathrm{EC}_{\mathrm{T}}$, which may be the case for the Mexico urban samples (Table 2). As a result, we do not suggest conversion between $E_{\mathrm{R}}$ and $\mathrm{EC}_{\mathrm{T}}$ when using the $\mathrm{NIOSH}$ 5 or similar temperature protocols that may be complicated by the "early split".

Measured EC values have also been shown to vary significantly among the various temperature protocols (Schauer et al., 2003; Subramanian et al., 2006; Cheng et al., 2010). Based on results from North America and Europe, ambient EC defined by the IMPROVE temperature protocol $\left(E_{\text {IMPROVE }}\right)$ was about $1.2 \sim 1.5$ times the value of 10 that defined by $\mathrm{NIOSH}\left(\mathrm{EC}_{\mathrm{NIOSH}}\right)$ when both using the transmittance correction (Cheng et al., 2010 and references therein). Few studies about the $\mathrm{EC}_{\text {IMPROVE }}$ to $\mathrm{EC}_{\mathrm{NIOSH}}$ ratio were available for Asia and quite different results have been reported. Results from Schauer et al. (2003) suggested that the ratio was about 1.5 for a regional background site in Korea whereas recent work by Cheng et al. (2010) indicated that the ratio may 15 be greater than 2.0 for Beijing, China. Importantly, the discrepancy between EC values determined by different methods was suggested to be strongly linked to brown carbon such that the discrepancy was larger when the contribution of brown carbon was high (Reisinger et al., 2008). As a result, the $\mathrm{EC}_{\text {IMPROVE }}$ to $\mathrm{EC}_{\mathrm{NIOSH}}$ ratio for Asia is expected to be higher than that for North America and Europe, due to the much 20 stronger emissions from the biomass burning and residential coal combustion (Bond et al., 2004; Venkataraman et al., 2005; Gustafsson et al., 2009) which are known to emit large amounts of brown carbon. When converting the MAC values in which EC was determined by the NIOSH temperature protocol with transmittance correction, different converting factors were used to account for the discrepancy caused by the temperature protocol: if the reported MAC was measured in North America or Europe, it was divided by $1.2 \sim 1.5$; if the reported MAC was measured in Asia, it was divided by 1.5 to obtain upper estimate of the "equivalence MAC".

Optical properties of elemental carbon and water-soluble organic carbon

Y. Cheng et al.

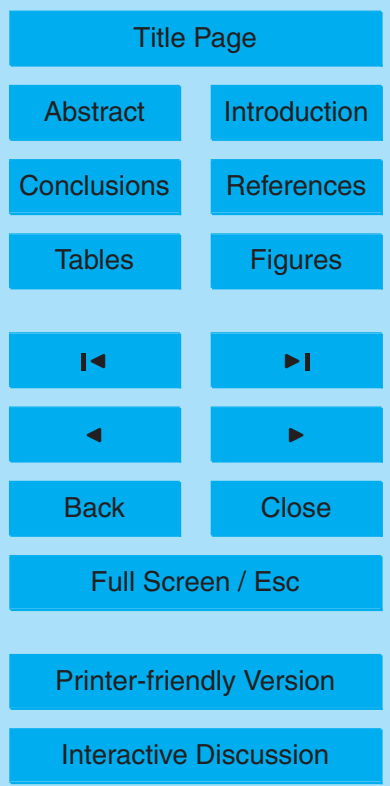


(2) Wavelength measurement correction. The wavelength $(\lambda)$ dependence of MAC can be represented as a power-law relationship using an Ångstrom exponent $(\AA ̊)$ :

$\mathrm{MAC}_{\lambda}=K \times \lambda^{-\AA}$

where $K$ is a constant that includes the aerosol mass concentration. A value of $\AA=1$ 5 was used for the present study. Then MAC measured at a given wavelength $\left(\mathrm{MAC}_{\lambda}\right)$ could be converted to that measured at $632 \mathrm{~nm}\left(\mathrm{MAC}_{632}\right)$ by Eq. (9):

$\mathrm{MAC}_{632}=\mathrm{MAC}_{\lambda} \times \frac{\lambda}{632}$

After incorporating the EC method conversion and the wavelength measurement correction, the whole converting approach to calculate the "equivalent MAC" from reported

equivalent $\mathrm{MAC}=\mathrm{MAC}_{\lambda} \times \frac{\lambda}{632} \times \frac{f_{\text {charring }}}{f_{\text {protocol }}}$

where $\lambda$ is the wavelength at which the reported MAC is measured; $f_{\text {charring }}$ is the converting factor of charring correction method, $f_{\text {charring }}=1.3 \sim 1.8$ for reported MAC in which EC was determined by the IMPROVE (or IMPROVE-A) temperature protocol with reflectance correction; $f_{\text {protocol }}$ is the converting factor of temperature protocol, $\mathrm{f}_{\text {protocol }}=1.2 \sim 1.5$ or 1.5 for reported MAC in which EC was determined by the NIOSH temperature protocol (or similar protocol such as STN) with transmittance correction, depending on where the reported MAC was measured.

Effects of the converting approach on the reported MAC values depend on the mea20 surement methods of both light absorption and EC concentration. As shown in Table 1, if the reported MAC were calculated by ATN measured at a wavelength greater than $632 \mathrm{~nm}$ (e.g., $880 \mathrm{~nm}$ ) together with EC defined by the IMPROVE temperature protocol with reflectance correction, the "equivalent MAC" would be substantially higher than the reported value, because the reported MAC would be increased by both the

Optical properties of elemental carbon and water-soluble organic carbon

Y. Cheng et al.

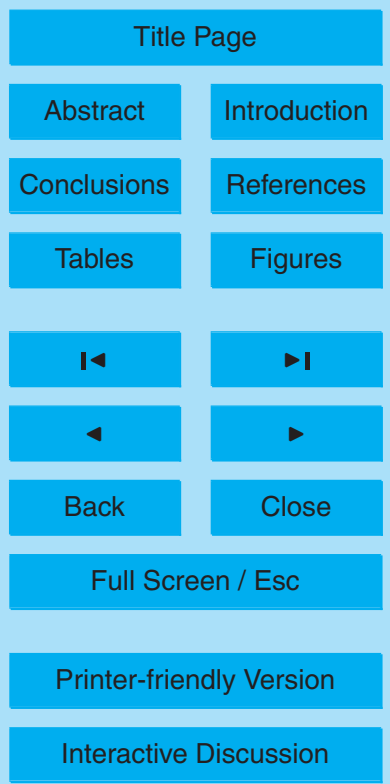


EC method conversion and the wavelength measurement correction process. In this case, the discrepancy between the reported MAC and the values obtained in this study would be reduced. For example, it seems that MAC values obtained in this study were about $1 \sim 2$ times higher than those reported by Babich et al. (2000); but the converting

5 approach increased the reported MAC values by a factor of $1.8 \sim 2.5$, indicating the MAC values reported by Babich et al. (2000) were in fact comparable with results from this study. However, the converting approach has little influence on the reported MAC values which were quantified by ATN measured at $880 \mathrm{~nm}$ together with EC defined by the NIOSH temperature protocol with transmittance correction, because of the oppo10 site effects of the EC method conversion and the wavelength measurement correction. The converting approach might also induce a larger discrepancy between the reported MAC values and results from this study. For example, MAC measured at a high-altitude site in India (Manora Peak, $24.7 \mathrm{~m}^{2} \mathrm{~g}^{-1}$ ) seems only a little lower compared to the value obtained in Beijing during the same season $\left(29.0 \mathrm{~m}^{2} \mathrm{~g}^{-1}\right)$; but after accounting for the 15 influence of measurement methods, the reported value was in fact less than $60 \%$ of that in Beijing.

\subsection{Effects of aerosol composition and sources}

Other factors in addition to measurement methods that influence MAC values can be investigated based on the converting approach described above, which would provide 20 deep insight into the optical properties of elemental (or black) carbon. The "equivalent MAC" shown in Table 1 could be classified into three groups according to their values. The first group includes an extremely high value $\left(55.6 \sim 69.5 \mathrm{~m}^{2} \mathrm{~g}^{-1}\right)$ measured in Philadelphia, PA during severe sulphate haze episodes occurred in the summer of 2002 (Jeong et al., 2004), and also includes results from Beijing (this study) and seven

25 American cities. In the first group, the upper estimates of the "equivalent MAC" were above (or close to) $30 \mathrm{~m}^{2} \mathrm{~g}^{-1}$, and the lower estimates were above $20 \mathrm{~m}^{2} \mathrm{~g}^{-1}$. The second group consists of eight "equivalent MAC" values measured in North America and Europe. In this group, the upper and lower estimates of the "equivalent MAC"

Optical properties of elemental carbon and water-soluble organic carbon

Y. Cheng et al.

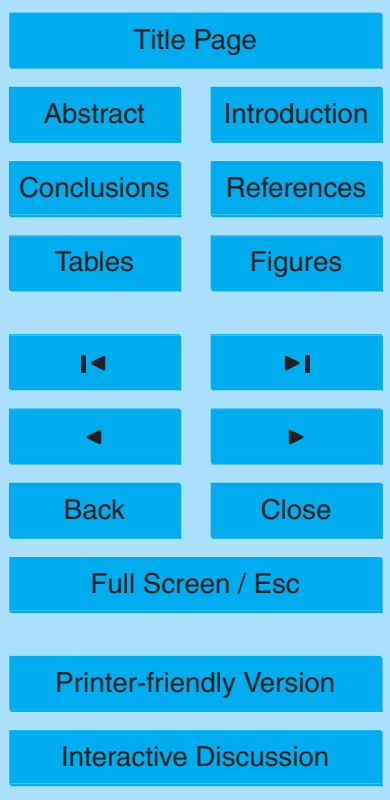


were between $21 \sim 26$ and $15 \sim 21 \mathrm{~m}^{2} \mathrm{~g}^{-1}$ respectively. The third group comprises results from Asia and those measured in North America and Europe during the periods impacted by biomass burning. The "equivalent MAC" values of this group were significantly lower. For example, the "equivalent MAC" measured in Philadelphia, PA during 5 a Canadian forest fire event was only between $5.4 \sim 6.7 \mathrm{~m}^{2} \mathrm{~g}^{-1}$ (Jeong et al., 2004).

In a recent review, Bond and Bergstrom (2006) suggested a value of $7.5 \mathrm{~m}^{2} \mathrm{~g}^{-1}$ for MAC of uncoated elemental carbon at $550 \mathrm{~nm}$, which was $6.5 \mathrm{~m}^{2} \mathrm{~g}^{-1}$ after accounting for the measurement wavelength by Eq. (9). As shown in Table 1, most of the "equivalent MAC" values were significantly higher than $6.5 \mathrm{~m}^{2} \mathrm{~g}^{-1}$. The discrepancy could be 10 attributed to three factors. The first is the enhancement of MAC due to the artifacts associated with the "filter-based" methods. A generally valid correction scheme for the enhancement effect is presently not available. One of the commonly used approaches was developed by Weingartner et al. (2003):

$\mathrm{MAC}_{\text {corrected }}=\frac{\text { MAC }}{C \times R(\mathrm{ATN})}$

15 The factor $C$ is used to correct for multiple scattering within a relatively clean filter. $A$ value of $C=2.14$ was suggested by Weingartner et al. (2003) for the same type of quartz filter as used in this study. $R($ ATN) corrects for the shadowing effect, which is empirically defined as:

$R($ ATN $)=\left(\frac{1}{f}-1\right) \times \frac{\ln (\text { ATN })-\ln (10 \%)}{\ln (50 \%)-\ln (10 \%)}+1$

20 Based on ATN values obtained in this study, $R($ ATN) was $0.87 \pm 0.05$ and $0.87 \pm 0.03$ during winter and summer respectively, if using $f$ values of 1.103 for winter and 1.114 for summer (Sandradewi et al., 2008). As a result, the enhancement factor, $C \times R(\mathrm{ATN})$, averaged $1.87 \pm 0.11$ and $1.87 \pm 0.06$ during winter and summer respectively. Comparably, Knox et al. (2009) found that the enhancement factor was about 2.4 based on
ACPD

$11,6221-6258,2011$

Optical properties of elemental carbon and water-soluble organic carbon

Y. Cheng et al.

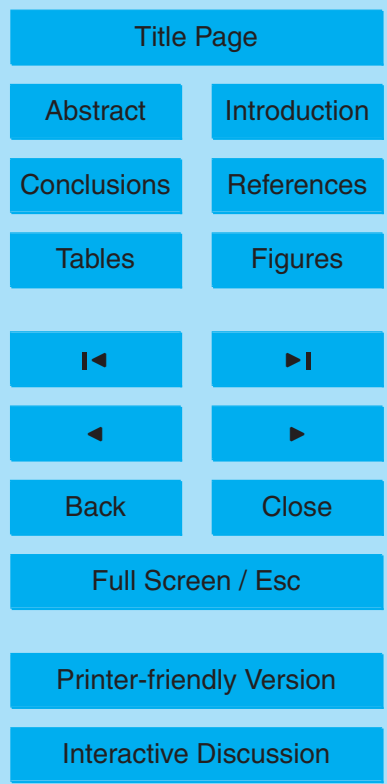


second factor is the uncertainties in the thermal-optical measurement of EC. It has been demonstrated that EC concentration would be under-estimated by the value that is operationally-defined by the thermal-optical method (with transmittance correction, Chow et al., 2004; Subramanian et al., 2006; Cheng et al., 2009), which was referred 5 to as the "systemic artifact" of thermal-optical method by Cheng et al. (2010). As far as we know, only Chow et al. (2004) and Cheng et al. (2009) quantitatively assessed the under-estimation of EC due to the "systemic artifact". However, both studies were based on a small number of samples collected at a single sampling site (31 Fresno samples and 20 Beijing samples, respectively). As a result, a reliable factor that ac10 counts for the "systemic artifact" is still not available. The third factor is the enhancement of MAC by coating with sulphate and /or organic carbon. Though not all of the sulphate is necessarily internally-mixed with EC, the relationship between MAC and the concentration of airborne sulphate could provide some valuable information about the effects of sulphate on the optical properties of EC. As shown in Fig. 2, the presence of sulphate increased the MAC when the sulphate concentration was below $10 \mathrm{\mu g} \mathrm{m}^{-3}$, whereas MAC and sulphate were only weekly related when the sulphate concentration was above $10 \mathrm{\mu g} \mathrm{m}^{-3}$. Figure 2 indicates that sulphate is probably internally-mixed with EC during summertime in Beijing and the enhancement of MAC due to coating with sulphate might not be significant beyond a certain coating thickness which is consistent with the theoretical predictions of Bond et al. (2006). Moreover, the extrapolated MAC value was $22.4 \mathrm{~m}^{2} \mathrm{~g}^{-1}$ when the sulphate concentration was zero, which was still much higher than that of uncoated EC $\left(6.5 \mathrm{~m}^{2} \mathrm{~g}^{-1}\right)$ suggested by Bond and Bergstrom (2006), even after considering the enhancement factor of MAC (1.87) due to the artifacts associated with the "filter-based" methods. The most likely cause is that other species in addition to sulphate also build up on EC. OC is another component in ambient aerosol that would be internally-mixed with EC, and laboratory studies have demonstrated that coating with OC would increase the MAC value of EC (Schnaiter et al., 2003, 2005). However, as shown in Fig. 3a, MAC only showed a moderate correlation with the OC concentration $\left(R^{2}=0.530\right)$, suggesting that enhancement of MAC caused by coating
Optical properties of elemental carbon and water-soluble organic carbon

Y. Cheng et al.

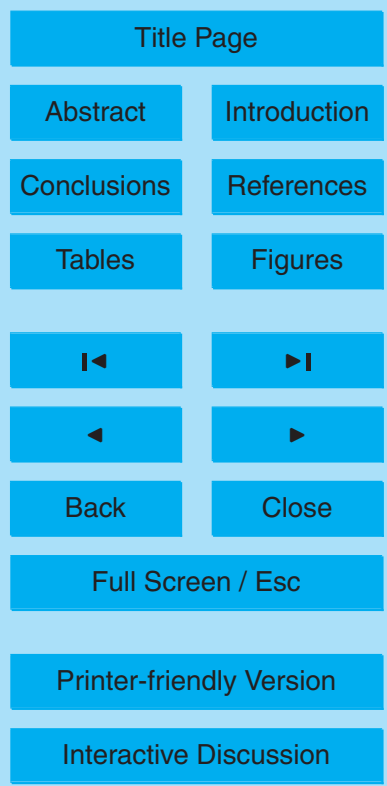


with OC does not seem significant. But it should be kept in mind that OC comprises both primary organic carbon (POC) that is directly emitted from combustion sources and secondary organic carbon (SOC) that is formed through atmospheric oxidation, either homogeneous or inhomogeneous. Moreover, SOC might be more likely to build 5 up on EC, especially when the inhomogeneous oxidation is important. This hypothesis was strongly supported by the high correlation $\left(R^{2}=0.910\right)$ between MAC and the OC to EC ratio which includes important information about the extent of secondary organic aerosol (SOA) production (Cheng et al., 2011, Fig. 3b). Figure 3b indicated that the enhancement of MAC is strongly linked to the coating by SOA. Moreover, the MAC 10 of uncoated EC can be estimated as the extrapolated value when the $\mathrm{OC}$ to EC ratio is zero, which was $10.50 \mathrm{~m}^{2} \mathrm{~g}^{-1}$. After correction by the enhancement factor (1.87) caused by the artifacts associated with the "filter-based" methods, the estimated MAC of uncoated EC was $5.6 \mathrm{~m}^{2} \mathrm{~g}^{-1}$, which is comparable with the value suggested by Bond and Bergstrom (2006).

15 The discussion above indicated that the unrealistically high values of MAC in Table 1 are mainly due to the artifacts associated with the "filter-based" methods and the enhancement by the coating with both sulphate and secondary organic carbon. Table 3 shows the upper and lower estimates of the "equivalent MAC" values of the three groups which have been corrected for the artifacts associated the "filter-based" methods. In the first group, the corrected "equivalent MAC" values $\left(11 \sim 21 \mathrm{~m}^{2} \mathrm{~g}^{-1}\right)$ were about $1 \sim 2$ time higher than the suggested value $\left(6.5 \mathrm{~m}^{2} \mathrm{~g}^{-1}\right)$ of uncoated EC (Bond and Bergstrom, 2006), indicating MAC values in this group were significantly enhanced by coating. In the second group, the corrected "equivalent MAC" values were in the range of $8 \sim 14 \mathrm{~m}^{2} \mathrm{~g}^{-1}$, indicating moderate enhancement by coating.

The "equivalent MAC" values in the third group were much lower. The MAC of EC in two Indian cities (Hisar and Allahabad), which were calculated by a similar method as used in this study, were less than $50 \%$ of that in Beijing during the same season (Sam and Sarin, 2009), suggesting EC in India was significantly less light-absorbing. The observed difference in optical properties indicates that the sources of EC were quite

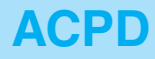

$11,6221-6258,2011$

Optical properties of elemental carbon and water-soluble organic carbon

Y. Cheng et al.

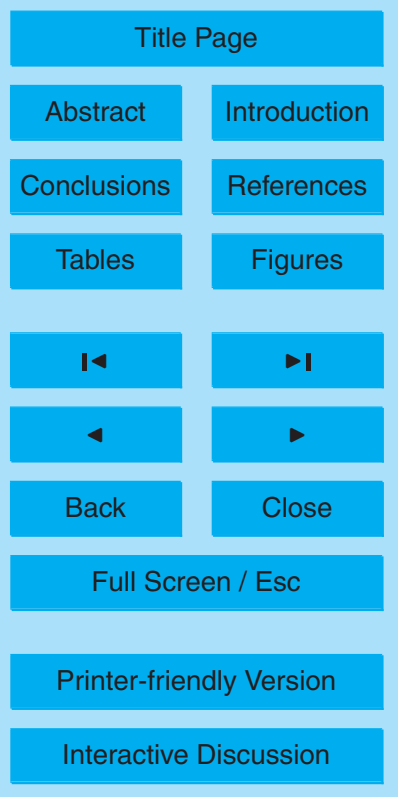


different in China than India. EC in India has been shown to be dominated by emissions from biomass burning (Venkataraman et al., 2005; Gustafsson et al., 2009), whereas coal burning (both industry and residential) is the largest source of EC emission in China (Bond et al., 2004; Cao et al., 2006). Biomass burning is known to emit a 5 significant amount of brown carbon that can not be directly measured by the currentlyused thermal-optical equipments. A fraction of brown carbon might be classified as $E C$, resulting in an artifact that increases the mass concentration of EC. On the other hand, the presence of brown carbon would not significantly influence the value of ATN, which is usually measured at wavelengths greater than $500 \mathrm{~nm}$ (Table 1). According 10 to Eq. (4), brown carbon is expected to decrease the value of MAC, indicating that the large amount of brown carbon in the atmosphere of India, which is emitted from biomass burning, is the most likely factor causing its significantly lower MAC values comparing with other regions. The hypothesis was further supported by results from North America and Europe such that the reported MAC values were much lower during 15 the periods impacted by biomass burning (Allen et al., 1999; Jeong et al., 2004; Krecl et al., 2007). As a result, the relatively low values of MAC in the third group were most likely due to the presence of brown carbon or the influences of biomass burning.

\subsection{Optical properties of water-soluble organic carbon}

WSOC averaged 7.3 and $3.4 \mu \mathrm{gC} \mathrm{m}^{-3}$, and constituted $22 \%$ and $39 \%$ of OC (mea20 sured by the denuded quartz filter), during winter and summer respectively (Cheng et al., 2011). The light absorption spectra over the wavelength range of 250 to $800 \mathrm{~nm}$ were recorded for the liquid extracts. The power law fit well in the wavelength range of 330-480 nm as shown in Fig. 4. The Ångstrom exponents calculated by Eq. (8) averaged $7.5 \pm 0.9$ and $7.0 \pm 0.8$ during winter and summer respectively. The Ångstrom 25 exponents were similar to those of humic-like substances (HULIS) isolated from the ambient aerosol in Amazonian biomass burning plumes (Hoffer et al., 2006), and are also comparable with those of the water extracts measured in the southeastern United States (Hecobian et al., 2010). The absorption spectra observed for the WSOC (Fig. 4)

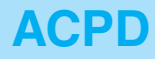

11, 6221-6258, 2011

Optical properties of elemental carbon and water-soluble organic carbon

Y. Cheng et al.

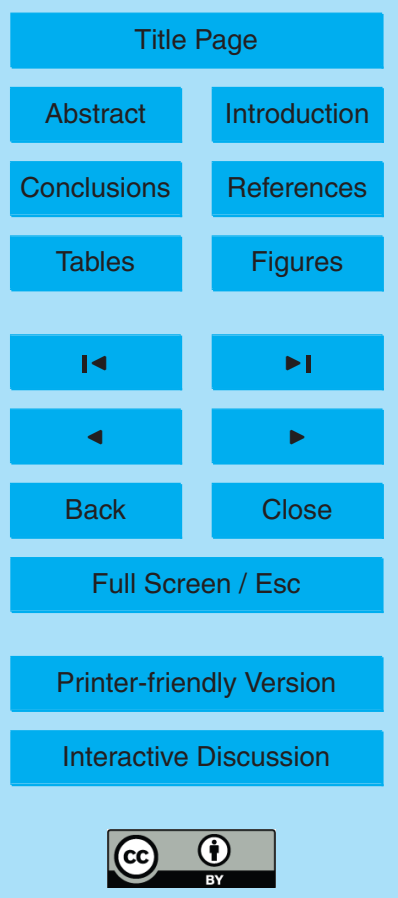


is characteristic of the brown carbon spectra with a sharply increasing absorption when wavelength decreases $\left(\sigma_{\mathrm{abs}} \sim \lambda^{-7}\right)$, which strongly supports that WSOC (or a fraction of WSOC) obtained in this study is brown carbon. In fact, a significant quantity of evidence for the atmospheric presence of brown carbon comes from the spectral prop5 erties of water extracts of continental aerosol (Andreae and Gelencsér, 2006; Lukács et al., 2007). Recently, a fraction of brown carbon was found to be non-water-soluble (Chen and Bond, 2010), but this fraction was not the focus of this study.

Though the light absorption spectra were recorded from 250 to $800 \mathrm{~nm}$, the absorption coefficient $\left(b_{\mathrm{abs}}\right)$ and mass absorption efficiency $\left(\sigma_{\mathrm{abs}}\right)$ of WSOC were calculated 10 at $365 \mathrm{~nm}$ (average between 360 and $370 \mathrm{~nm}$ ) by Eqs. (5) to (7). This wavelength was chosen to avoid interferences from non-organic compounds such as nitrate and to maintain consistency with previously published results (Lukács et al., 2007; Hecobian et al., 2010). During the winter, $b_{\mathrm{abs}}$ and WSOC correlated well with a slope of $1.83 \pm 0.03 \mathrm{~m}^{2} \mathrm{~g}^{-1}\left(R^{2}=0.977\right)$, whereas the regression between $b_{\mathrm{abs}}$ and WSOC 15 showed a slope of $0.70 \pm 0.03 \mathrm{~m}^{2} \mathrm{~g}^{-1}$ during the summer $\left(R^{2}=0.734\right.$, Fig. 5). Cheng et al. (2011) found that WSOC correlated well $\left(R^{2}=0.84 \sim 0.94\right)$ with the secondary organic aerosol (SOA) predicted by the EC-tracer method, indicating a substantial fraction of WSOC is SOA in Beijing; moreover, the estimated SOA accounted for about 40 and $50 \%$ of organic aerosol (OA, measured by the denuded quartz filter) during winter and summer respectively, suggesting considerable SOA production despite the low temperature in winter. Importantly, the emission of biogenic volatile organic compounds (BVOCs) in Beijing showed a distinct seasonal pattern such that the BVOCs emission reached a maximum in summer (e.g., $4.4 \times 10^{9} \mathrm{gC}$ in July) whereas the emission was much lower during winter (e.g., $6.3 \times 10^{6} \mathrm{gC}$ in January, Wang et al., 2003). As a result, 25 anthropogenic volatile organic compounds (AVOCs) should be more important as the precursors of SOA during winter compared with summer. Given the fact that WSOC is strongly linked to SOA in Beijing, the difference in the precursors of SOA is a most likely cause of the discrepancy in the $\sigma_{\mathrm{abs}}$ of WSOC during winter and summer.

Optical properties of elemental carbon and water-soluble organic carbon

Y. Cheng et al.

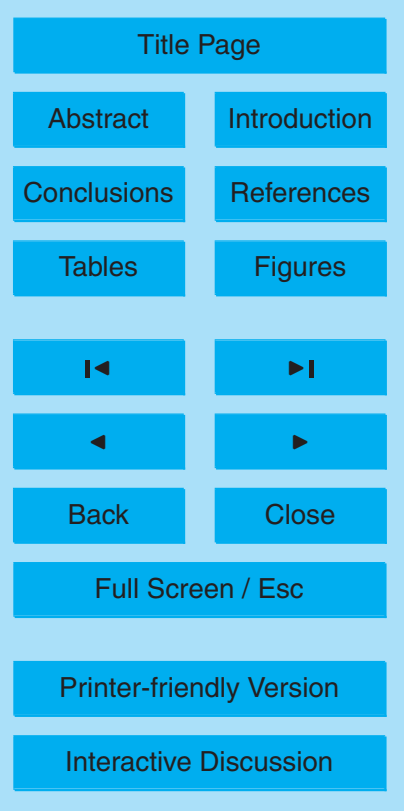


Previous studies suggested that biomass burning is another source of WSOC (Sullivan et al., 2006; Weber et al., 2007; Snyder et al., 2009). Effects of biomass burning on the $\sigma_{\mathrm{abs}}$ of WSOC could be illustrated by results from Hecobian et al. (2010). In the southeastern United States, the $\sigma_{\text {abs }}$ (measured at $365 \mathrm{~nm}$ using the same method as 5 used in this study) were $0.31 \mathrm{~m}^{2} \mathrm{~g}^{-1}\left(0.21 \sim 0.42 \mathrm{~m}^{2} \mathrm{~g}^{-1}\right)$ and $0.29\left(0.26 \sim 0.32 \mathrm{~m}^{2} / \mathrm{g}\right)$ for urban and rural sites respectively, when the contribution of biomass burning was not important (identified by levoglucosan $<50 \mathrm{ng} \mathrm{m}^{-3}$, typically in the summer); whereas the $\sigma_{\text {abs }}$ averaged $0.70 \mathrm{~m}^{2} \mathrm{~g}^{-1}\left(0.62 \sim 0.84 \mathrm{~m}^{2} \mathrm{~g}^{-1}\right)$ and $0.62\left(0.57 \sim 0.67 \mathrm{~m}^{2} \mathrm{~g}^{-1}\right)$ for urban and rural sites respectively, when the influence of biomass burning was sig10 nificant (identified by levoglucosan $>50 \mathrm{ng} \mathrm{m}^{-3}$, typically in the winter and spring). These results seem to indicate that WSOC emitted from biomass burning is more light-absorbing compared with that formed by atmospheric reaction. This hypothesis was supported by the much higher $\sigma_{\text {abs }}$ value in Beijing $\left(0.70 \sim 1.83 \mathrm{~m}^{2} \mathrm{~g}^{-1}\right)$ where the levoglucosan concentration was above $100 \mathrm{ng} \mathrm{m}^{-3}$ all year round (averaging 307 $15 \mathrm{ng} / \mathrm{m}^{3}$, Zhang et al., 2008). The high levoglucosan concentration throughout the year was mainly due to the agricultural waste and firewood that is commonly consumed as domestic fuel in the rural areas of Beijing as well as in neighboring provinces, which resulted in a background contribution of biomass burning to Beijing aerosol existing throughout the year (Zhang et al., 2008). Moreover, Beijing might also be heavily im20 pacted by the open burning of agricultural waste in nearby provinces (open burning is prohibited in Beijing), which was significant only in the harvest season such as early summer when wheat is harvested and autumn when maize is harvested (Duan et al., 2004; He et al., 2006; Zhang et al., 2008; Li et al., 2010). Recent results from source apportionment by CMB (chemical mass balance) suggested that biomass burning accounted for 11 and $26 \%$ of ambient OC in Beijing during summer (not within the period when wheat is harvested) and winter respectively, which was consistent with the levoglucosan to OC ratio $(0.6$ and $1.4 \%$ during summer and winter respectively, Wang et al., 2009). The higher contribution in winter, when there are no harvest activities, should be due to the large amount of biofuels used for domestic heating in northern

\section{ACPD}

$11,6221-6258,2011$

Optical properties of elemental carbon and water-soluble organic carbon

Y. Cheng et al.

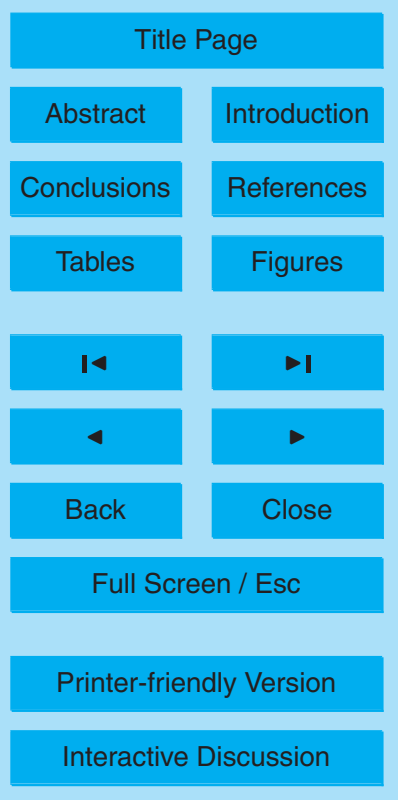


China. On the other hand, He et al. (2006) found that the levoglucosan to OC ratio was comparable (about $0.2 \%$ ) during winter and summer (not within the harvest season), indicating the contribution of biomass burning to ambient $\mathrm{OC}$ in Beijing was comparable during winter and summer. A similar seasonal pattern of the levoglucosan to OC ratio 5 was also found by Zhang et al. (2008). These results suggest that the biomass burning contribution and its seasonal pattern is still highly uncertain for the Beijing region. Given the fact that the WSOC in Beijing was dominated by SOA during both winter and summer (Cheng et al., 2011), it could only be concluded that biomass burning might be responsible for the much higher absolute value of $\sigma_{\text {abs }}$ in Beijing comparing with the

10 southeastern United States; whether it contributes to the seasonal variation of $\sigma_{\mathrm{abs}}$ in Beijing is still inconclusive.

\section{Conclusions}

The MAC of EC in Beijing was quantified using a thermal-optical carbon analyzer. The absorption measurement was performed at $632 \mathrm{~nm}$ and the EC concentration was determined by the IMPROVE-A temperature protocol with transmittance charring correction. The MAC was 29.0 and $32.0 \mathrm{~m}^{2} \mathrm{~g}^{-1}$ during winter and summer respectively. The unrealistically high MAC values were mainly due to two factors. The first is the artifacts associated with the "filter-based" methods, such as the multiple scattering within a relatively clean filter and the shadowing effect. The enhancement factor was 1.87 , which was calculated following Weingartner et al. (2003) and Sandradewi et al. (2008). The second is the enhancement of MAC by coating. MAC correlated well with the OC to EC ratio $\left(R^{2}=0.91\right)$ which includes important information about the extent of secondary organic aerosol (SOA) production, indicating the enhancement of MAC by coating with SOA. The MAC value also increased with sulphate $\left(R^{2}=0.84\right)$ when the sulphate concentration was below $10 \mathrm{\mu g} \mathrm{m}^{-3}$. However, MAC and sulphate were only weekly related when the sulphate concentration exceeding $10 \mu \mathrm{g} \mathrm{m}^{-3}$. The extrapolated MAC value was $10.5 \mathrm{~m}^{2} \mathrm{~g}^{-1}$ when the OC to EC ratio is zero, which was comparable with the value

Optical properties of elemental carbon and water-soluble organic carbon

Y. Cheng et al.

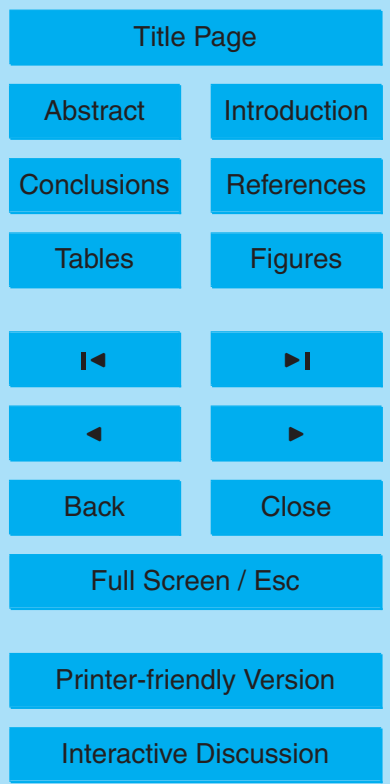


suggested for uncoated EC $\left(6.5 \mathrm{~m}^{2} \mathrm{~g}^{-1}\right.$, Bond and Bergstrom, 2006) after correction by the enhancement factor (1.87) caused by the artifacts associated with the "filter-based" methods. On the other hand, the extrapolated MAC value was $22.4 \mathrm{~m}^{2} \mathrm{~g}^{-1}$ when the sulphate concentration is zero, which was still significantly higher than the suggested 5 value of uncoated EC even after accounting for the artifacts associated with the "filterbased" methods. These results indicated that the MAC of EC in Beijing was enhanced by the coating with both SOA and sulphate, and the enhancement was more strongly linked to SOA.

A converting approach, including the EC method conversion and the wavelength measurement correction, was developed to account for the discrepancy caused by measurements methods of both light absorption and EC concentration. Based on this approach, previously published MAC values were converted to the "equivalent MAC", which is the estimated value if using the same measurement methods (of both ATN and $\mathrm{EC}_{s}$ ) as used in this study. With respect to most of the results from North America and Europe, the upper estimates of the "equivalent MAC" values were typically above $20 \mathrm{~m}^{2} \mathrm{~g}^{-1}$, which was attributed to the artifacts associated with the "filter-based" methods and the enhancement by coating. On the other hand, the "equivalent MAC" values were much lower in India (below $10 \mathrm{~m}^{2} \mathrm{~g}^{-1}$ for two urban sites, Table 1), probably due to the large amounts of brown carbon emitted from biomass burning. This hypothesis was 20 strongly supported by results from North America and Europe such that the reported MAC values were much lower during the periods impacted by biomass burning.

The absorption spectra of WSOC in Beijing was characteristic of the brown carbon spectra with a sharply increasing absorption when wavelength decreases $\left(\sigma_{\mathrm{abs}} \sim \lambda^{-7}\right)$. The $\sigma_{\text {abs }}$ of WSOC (measured at $365 \mathrm{~nm}$ ) was 1.83 and $0.70 \mathrm{~m}^{2} \mathrm{~g}^{-1}$ during winter and 25 summer respectively. Our previous study demonstrated that WSOC in Beijing was strongly linked to SOA and the SOA to OA ratio was comparable during winter and summer (40\% and $50 \%$ respectively, Cheng et al., 2011). Moreover, the emission of biogenic volatile organic compounds (BVOCs) in Beijing was approximately 1000 times lower during winter compared with summer, indicating that anthropogenic volatile
Optical properties of elemental carbon and water-soluble organic carbon

Y. Cheng et al.

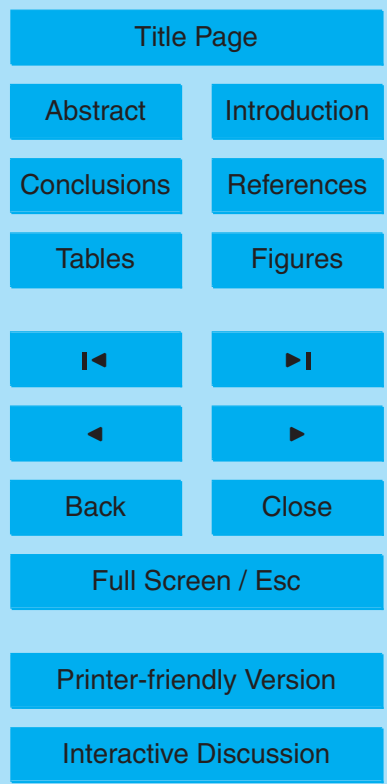


organic compounds (AVOCs) should be more important as the precursors of SOA in winter. As a result, the observed seasonal pattern of the $\sigma_{\text {abs }}$ of WSOC was attributed to the difference in the precursors of SOA. The $\sigma_{\mathrm{abs}}$ of WSOC in Beijing was found to be much higher than results from the southeastern United States which were obtained 5 using the same method as used in this study, perhaps due to the influence of biomass burning.

Acknowledgements. This work was supported by the National Natural Science Foundation of China (20625722), the National 973 Program of China (2010CB951803), and the Foundation for the Author of National Excellent Doctoral Dissertation of PR China (2007B57). The authors 10 would like to acknowledge visiting scholar Charles N. Freed for revising the paper, and would also like to acknowledge Chen Lai-guo, Marcus Trail, and Colin Boswell for their help in the analysis.

\section{References}

Alexander, D. T. L., Crozier, P. A., and Anderson, J. R.: Brown carbon spheres in East Asian outflow and their optical properties, Science, 321, 833-836, 2008.

Allen, G. A., Lawrence, J., and Koutrakis, P.: Field validation of a semi-continuous method for aerosol black carbon (Aethalometer) and temporal patterns of summertime hourly black carbon measurements in southwestern PA, Atmos. Environ., 33, 817-823, 1999.

Andreae, M. O. and Crutzen, P. J.: Atmospheric aerosols: Biogeochemical sources and role in atmospheric chemistry, Science, 276, 1052-1058, 1997.

Andreae, M. O. and Gelencsér, A.: Black carbon or brown carbon? The nature of lightabsorbing carbonaceous aerosols, Atmos. Chem. Phys., 6, 3131-3148, doi:10.5194/acp6-3131-2006, 2006.

Arnott, W. P., Moosmüller, H., Sheridan, P. J., Ogren, J. A., Raspet, R., Slaton, W. V., Hand, J. L., Kreidenweis, S. M., and Collett, J. L.: Photoacoustic and filter-based ambient aerosol light absorption measurements: instrument comparisons and the role of relative humidity, $\mathrm{J}$. Geophys. Res., 108(D1), 4034, doi:10.1029/2002JD002165, 2003.

Babich, P., Davey, M., Allen, G., and Koutrakis, P.: Method comparisons for particulate nitrate,

\section{ACPD}

$11,6221-6258,2011$

Optical properties of elemental carbon and water-soluble organic carbon

Y. Cheng et al.

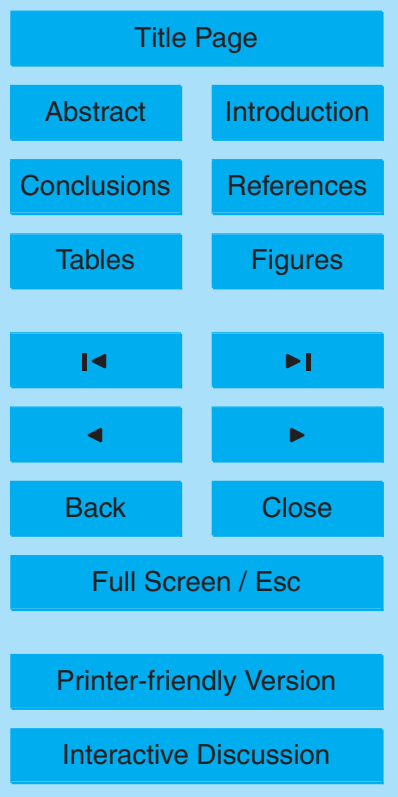


elemental carbon, and $\mathrm{PM}_{2.5}$ mass in seven US cities, J. Air Waste Manage., 50, 1095-1105, 2000.

Bergstrom, R. W., Ackerman, T. P., and Richards, L. W.: Optical Properties of particulate elemental carbon, in: Particulate carbon: atmospheric life cycle, edited by: Wolff, G. T. and Klimisch, R. L., Plenum Press, New York, 1982.

Bergstrom, R. W., Pilewskie, P., Russell, P. B., Redemann, J., Bond, T. C., Quinn, P. K., and Sierau, B.: Spectral absorption properties of atmospheric aerosols, Atmos. Chem. Phys., 7, 5937-5943, doi:10.5194/acp-7-5937-2007, 2007.

Birch, M. E. and Cary, R. A.: Elemental carbon-based method for monitoring occupational exposures to particulate diesel exhaust, Aerosol Sci. Technol., 25, 221-241, 1996.

Bond, T. C.: Spectral dependence of visible light absorption by carbonaceous particles emitted from coal combustion, Geophys. Res. Lett., 28, 4075-4078, doi:10.1029/2001GL013652, 2001.

Bond, T. C. and Bergstrom, R. W.: Light absorption by carbonaceous particles: an investigative review, Aerosol Sci. Technol., 40, 27-67, 2006.

Bond, T. C., Habib, G., and Bergstrom, R. W.: Limitations in the enhancement of visible light absorption due to mixing state, J. Geophys. Res., 111, D20211, doi:10.1029/2006JD007315, 2006.

Bond, T. C., Streets, D. G., Yarber, K. F., Nelson, S. M., Woo, J. H., and Klimont, Z.: A technology-based global inventory of black and organic carbon emissions from combustion, J. Geophys. Res., D14, D14203, doi:10.1029/2003JD003697, 2004.

Cao, G. L., Zhang, X. Y., and Zheng, F. C.: Inventory of black carbon and organic carbon emissions from China, Atmos. Environ., 40, 6516-6527, 2006.

Chakrabarty, R. K., Moosmüller, H., Garro, M. A., Arnott, W. P., Walker, J., Susott, R. A., Babbitt, R. E., Wold, C. E., Lincoln, E. N., and Hao, W. M.: Emissions from the laboratory combustion of wildland fuels: particle morphology and size, J. Geophys. Res., 111, D07204, doi:10.1029/2005JD006659, 2006.

Chakrabarty, R. K., Moosmüller, H., Chen, L.-W. A., Lewis, K., Arnott, W. P., Mazzoleni, C., Dubey, M. K., Wold, C. E., Hao, W. M., and Kreidenweis, S. M.: Brown carbon in tar balls from smoldering biomass combustion, Atmos. Chem. Phys., 10, 6363-6370, doi:10.5194/acp-106363-2010, 2010.

Chen, Y. and Bond, T. C.: Light absorption by organic carbon from wood combustion, Atmos. Chem. Phys., 10, 1773-1787, doi:10.5194/acp-10-1773-2010, 2010.

Optical properties of elemental carbon and water-soluble organic carbon

Y. Cheng et al.

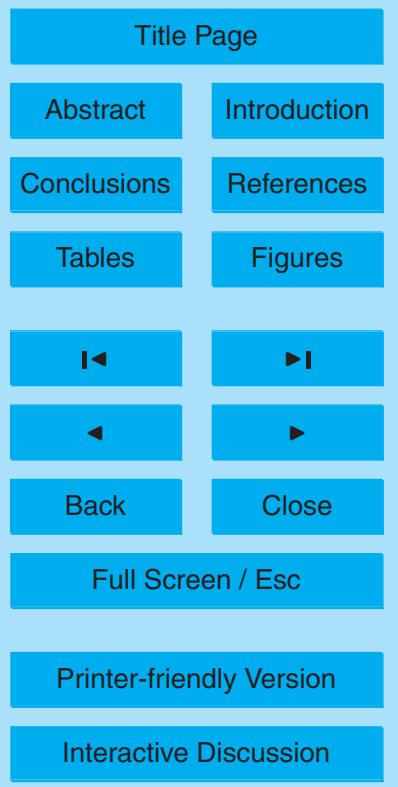


Cheng, Y., He, K. B., Duan, F. K., Zheng, M., Ma, Y. L., and Tan, J. H.: Positive sampling artifact of carbonaceous aerosols and its influence on the thermal-optical split of OC/EC, Atmos. Chem. Phys., 9, 7243-7256, doi:10.5194/acp-9-7243-2009, 2009.

Cheng, Y., He, K. B., Duan, F. K., Zheng, M., Ma, Y. L., Tan, J. H., and Du, Z. Y.: Improved measurement of carbonaceous aerosol: evaluation of the sampling artifacts and intercomparison of the thermal-optical analysis methods, Atmos. Chem. Phys., 10, 8533-8548, doi:10.5194/acp-10-8533-2010, 2010.

Cheng, Y., He, K. B., Duan, F. K., Zheng, M., Du, Z. Y., Ma, Y. L., and Tan, J. H.: Ambient organic carbon to elemental carbon ratios: influences of the measurement methods and implications, Atmos. Environ., doi:10.1016/j.atmosenv.2011.01.064, 2011.

Chow, J. C., Watson, J. G., Chen, L. A., Arnott, W. P., and Moosmüller, H.: Equivalence of elemental carbon by thermal/optical reflectance and transmittance with different temperature protocols, Environ. Sci. Technol., 38, 4414-4422, 2004.

Chow, J. C., Watson, J. G., Pritchett, L. C., Pierson, W. R., Frazier, C. A., and Purcell, R. G.: 15 The DRI Thermal/Optical Reflectance carbon analysis system: description, evaluation and applications in US air quality studies, Atmos. Environ., 27A, 1185-1201, 1993.

Clarke, A., McNaughton, C., Kapustin, V., Shinozuka, Y., Howell, S., Dibb, J., Zhou, J., Anderson, B., Brekhovskikh, V., Turner, H., and Pinkerton, M.: Biomass burning and pollution aerosol over North America: organic components and their influence on spectral optical properties and humidification response, J. Geophys. Res., 112, D12S18, doi:10.1029/2006JD007777, 2007.

Duan, F. K., Liu, X. D., Yu, T., and Cachier, H.: Identification and estimate of biomass burning contribution to the urban aerosol organic carbon concentrations in Beijing, Atmos. Environ., 38, 1275-1282, 2004.

Gelencsér, A., Hoffer, A., Kiss, G., Tombácz, E., Kurdi, R., and Bencze, L.: In-situ formation of light-absorbing organic matter in cloud water, J. Atmos. Chem., 45, 25-33, 2003.

Gustafsson, O., Kruså, M., Zencak, Z., Sheesley, R. J., Granat, L., Engström, E., Praveen, P. S., Rao, P. S. P., Leck, C., and Rodhe, H.: Brown clouds over south Asia: biomass or fossil fuel combustion?, Science, 323, 495-498, 2009.

so Hand, J. L., Malm, W. C., Laskin, A., Day, D., Lee, T., Wang, C., Carrico, C., Carrillo, J., Cowin, J. P., Collett, J., and ledema, M. J.: Optical, physical, and chemical properties of tar balls observed during the Yosemite Aerosol Characterization Study, J. Geophys. Res., 110, D21210, doi:10.1029/2004JD005728, 2005.

\section{ACPD}

11, 6221-6258, 2011

Optical properties of elemental carbon and water-soluble organic carbon

Y. Cheng et al.

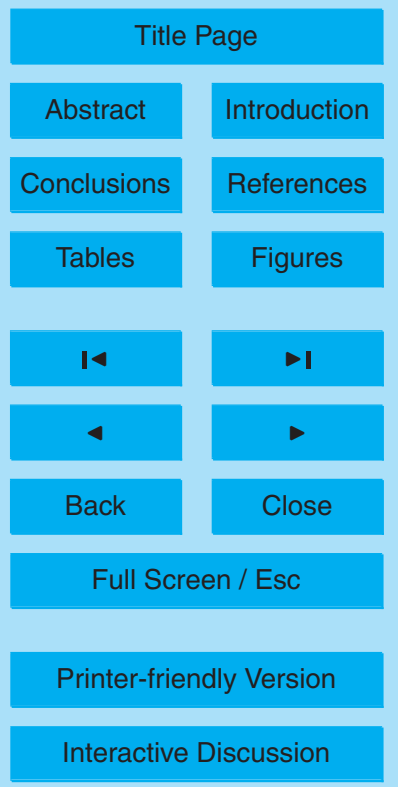


Hansen, A. D. A. and Novakov, T.: Real-time measurement of aerosol black carbon during the carbonaceous species methods comparison study, Aerosol Sci. Technol., 12, 194-199, 1990.

He, L. Y., Hu, M., Huang, X. F., Zhang, Y. H., and Tang, X. Y.: Seasonal pollution characteristics 5 of organic compounds in atmospheric fine particles in Beijing, Sci. Total. Environ., 359, 167176, 2006.

Hecobian, A., Zhang, X., Zheng, M., Frank, N., Edgerton, E. S., and Weber, R. J.: WaterSoluble Organic Aerosol material and the light-absorption characteristics of aqueous extracts measured over the Southeastern United States, Atmos. Chem. Phys., 10, 5965-5977, doi:10.5194/acp-10-5965-2010, 2010.

Hoffer, A., Gelencsr, A., Guyon, P., Kiss, G., Schmid, O., Frank, G. P., Artaxo, P., and Andreae, M. O.: Optical properties of humic-like substances (HULIS) in biomass-burning aerosols, Atmos. Chem. Phys., 6, 3563-3570, doi:10.5194/acp-6-3563-2006, 2006.

Husain, L., Dutkiewicz, V. A., Khan, A., and Ghauri, B. M.: Characterization of carbonaceous aerosols in urban air, Atmos. Environ., 41, 6872-6883, 2007.

Jacobson, M. Z.: Isolating nitrated and aromatic aerosols and nitrated aromatic gases as sources of ultraviolet light absorption, J. Geophys. Res., 104, 3527-3542, doi:10.1029/1998JD100054, 1999.

Jacobson, M. Z.: Strong radiative heating due to the mixing state of black carbon in atmospheric aerosols, Nature, 409, 695-697, 2001.

Jeong, C. H., Hopke, P. K., Kim, E., and Lee, D. W.: The comparison between thermal-optical transmittance elemental carbon and Aethalometer black carbon measured at multiple monitoring sites, Atmos. Environ., 38, 5193-5204, 2004.

Kirchstetter, T. W., Novakov, T., and Hobbs, P. V.: Evidence that the spectral dependence of 25 light absorption by aerosols is affected by organic carbon, J. Geophys. Res., 109, D21208, doi:10.1029/2004JD004999, 2004.

Knox, A., Evans, G. J., Brook, J. R., Yao, X., Jeong, C. H., Godri, K. J., Sabaliauskas, K., and Slowik, J. G.: Mass absorption cross-section of ambient black carbon aerosol in relation to chemical age, Aerosol Sci. Technol., 43, 522-532, 2009.

$30 \mathrm{Krecl}$, P., Strom, J., and Johansson, C.: Carbon content of atmospheric aerosols in a residential area during the wood combustion season in Sweden, Atmos. Environ., 41, 6974-6985, 2007.

Li, W. J., Shao, L. Y., and Buseck, P. R.: Haze types in Beijing and the influence of agricul-

Optical properties of elemental carbon and water-soluble organic carbon

Y. Cheng et al.

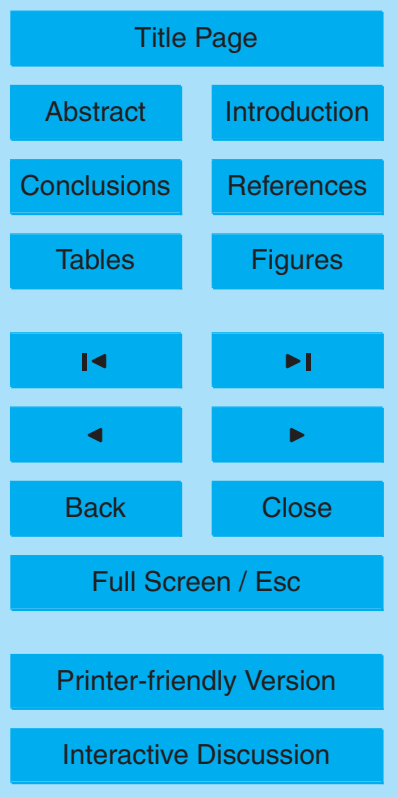

Interactive Discussion 
tural biomass burning, Atmos. Chem. Phys., 10, 8119-8130, doi:10.5194/acp-10-8119-2010, 2010.

Lim, H. J., Turpin, B. J., Edgerton, E., Hering, S. V., Allen, G., Maring, H., and Solomon, P.: Semicontinuous aerosol carbon measurements: comparison of Atlanta Supersite measure5 ments, J. Geophys. Res., 108(D7), 8419, doi:10.1029/2001JD001214, 2003.

Liousse, C., Cachier, H., and Jennings, S. G.: Optical and thermal measurements of black carbon aerosol content in different environments: variation of the specific attenuation crosssection, sigma $(\sigma)$, Atmos. Environ., 27A, 1203-1211, 1993.

Lukács, H., Gelencsér, A., Hammer, S., Puxbaum, H., Pio, C., Legrand, M., Kasper-Giebl, A., Handler, M., Limbeck, A., Simpson, D., and Preunkert, S.: Seasonal trends and possible sources of brown carbon based on 2-year aerosol measurements at six sites in Europe, J. Geophys. Res., 112, D23S18, doi:10.1029/2006JD008151, 2007.

Menon, S., Hansen, J., Nazarenko, L., and Luo, Y. F.: Climate effects of black carbon aerosols in China and India, Science, 297, 2250-2253, 2002.

Petzold, A., Schloesser, H., Sheridan, P. J., Arnott, W. P., Ogren, J. A., and Virkkula, A.: Evaluation of multiangle absorption photometry for measuring aerosol light absorption, Aerosol Sci. Technol., 39, 40-51, 2005.

Pöschl, U.: Atmospheric aerosols: composition, transformation, climate and health effects, Angew. Chem. Int. Ed., 44, 7520-7540, 2005.

20 Pósfai, M., Gelencsér, A., Simonics, R., Arató, K., Li, J., Hobbs, P. V., and Buseck, P. R.: Atmospheric tar balls: particles from biomass and biofuel burning, J. Geophys. Res., 109, D06213, doi:10.1029/2003JD004169, 2004.

Quincey, P., Butterfield, D., Green, D., Coyle, M., and Cape, C. N.: An evaluation of measurement methods for organic, elemental and black carbon in ambient air monitoring sites, Atmos. Environ., 43, 5085-5091, 2009.

Ram, K. and Sarin, M. M.: Absorption coefficient and site-specific mass absorption efficiency of elemental carbon in aerosols over urban, rural, and high-altitude sites in India, Environ. Sci. Technol., 43, 8233-8239, 2009.

Ramanathan, V. and Carmichael, G.: Global and regional climate changes due to black carbon, Nat. Geosci., 1, 221-227, 2008.

Ramanathan, V., Crutzen, P. J., Kiehl, J. T., and Rosenfeld, D.: Aerosols, climate, and the hydrological cycle, Science, 294, 2119-2124, 2001.

Rattigan, O. V., Dirk Felton, H., Bae, M. S., Schwab, J. J., and Demerjian, K. L.: Multi-year

Optical properties of elemental carbon and water-soluble organic carbon

Y. Cheng et al.

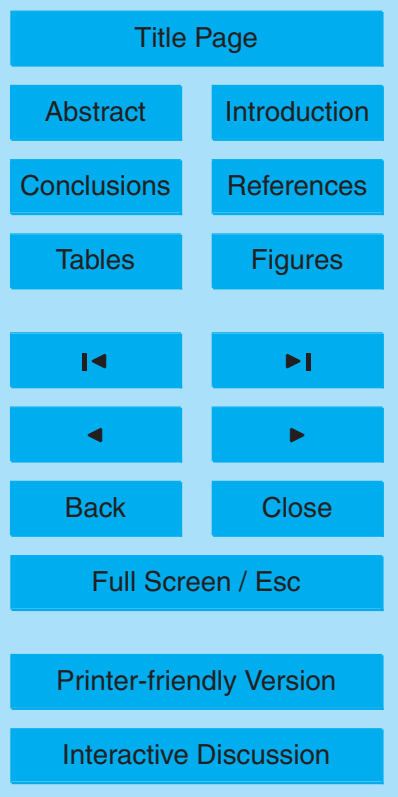

Interactive Discussion 
hourly $\mathrm{PM}_{2.5}$ carbon measurements in New York: diurnal, day of week and seasonal patterns, Atmos. Environ., 44, 2043-2053, 2010.

Reisinger, P., Wonaschütz, A., Hitzenberger, R., Petzold, A., Bauer, H., Jankowski, N., Puxbaum, H., Chi, X., and Maenhaut, W.: Intercomparison of measurement techniques 5 for black or elemental carbon under urban background conditions in wintertime: influence of biomass combustion, Environ. Sci. Technol., 42, 884-889, 2008.

Rice, J.: Comparison of integrated filter and automated carbon aerosol measurements at research triangle park, North Carolina, Aerosol Sci. Technol., 38, 23-36, 2004.

Weber, R. J., Sullivan, A. P., Peltier, R. E., Russell, A., Yan, B., Zheng, M., de Gouw, J., Warneke, C., Brock, C., Holloway, J. S., Atlas, E. L., and Edgerton, E.: A study of secondary organic aerosol formation in the anthropogenic-influenced southeastern United States, J. Geophys. Res., 112, D13302, doi:10.1029/2007JD008408, 2007.

Sandradewi, J., Prevot, A. S. H., Weingartner, E., Schmidhauser, R., Gysel, M., and Baltensperger, U.: A study of wood burning and traffic aerosols in an Alpine valley using a multi-wavelength Aethalometer, Atmos. Environ., 42, 101-112, 2008.

Schauer, J. J., Mader, B. T., DeMinter, J. T., Heidemann, G., Bae, M. S., Seinfeld, J. H., Flagan, R, C., Cary, R. A., Smith, D., Huebert, B. J., Bertram, T., Howell, S., Kline, J. T., Quinn, P., Bates, T., Turpin, B., Lim, H. J., Yu, J. Z., Yang, H., and Keywood, M. D.: ACE-Asia intercomparison of a thermal-optical method for the determination of particle-phase organic and elemental carbon, Environ. Sci. Technol., 37, 993-1001, 2003.

Schnaiter, M., Horvath, H., Möhler, O., Naumann, K. H., Saathoff, H., and Schöck, O. W.: UVVIS-NIR spectral optical properties of soot and soot-containing aerosols, J. Aerosol Sci., 34, 1421-1444, 2003.

Schnaiter, M., Linke, C., Möhler, O., Naumann, K. H., Saathoff, H., Wagner, R., Schurath, U., and Wehner, B.: Absorption amplification of black carbon internally mixed with secondary organic aerosol, J. Geophys. Res., 110, D19204, doi:10.1029/2005JD006046, 2005.

Schnaiter, M., Gimmler, M., Llamas, I., Linke, C., Jäger, C., and Mutschke, H.: Strong spectral dependence of light absorption by organic carbon particles formed by propane combustion, Atmos. Chem. Phys., 6, 2981-2990, doi:10.5194/acp-6-2981-2006, 2006.

30 Sciare, J., Cachier, H., Oikonomou, K., Ausset, P., Sarda-Estéve, R., and Mihalopoulos, N.: Characterization of carbonaceous aerosols during the MINOS campaign in Crete, July-August 2001: a multi-analytical approach, Atmos. Chem. Phys., 3, 1743-1757, doi:10.5194/acp-3-1743-2003, 2003.

Optical properties of elemental carbon and water-soluble organic carbon

Y. Cheng et al.

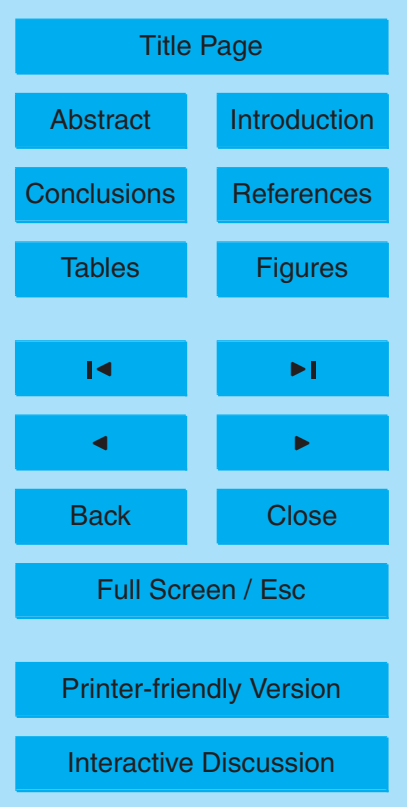

Interactive Discussion 
Sharma, S, Brook, J. R., Cachier, H., Chow, J., Gaudenzi, A., and Lu, G.: Light absorption and thermal measurements of black carbon in different regions of Canada, J. Geophys. Res., 107(D24), 4771, doi:10.1029/2002JD002496, 2002.

Snyder, D. C. and Schauer, J. J.: An inter-comparison of two black carbon aerosol instruments 5 and a semi-continuous elemental carbon instrument in the urban environment, Aerosol Sci. Technol., 41, 463-474, 2007.

Snyder, D. C., Rutter, A. P., Collins, R., Worley, C., and Schauer, J. J.: Insights into the origin of water soluble organic carbon in atmospheric fine particulate matter, Aerosol Sci. Technol., 43, 1099-1107, 2009.

10 Subramanian, R., Khlystov, A. Y., and Robinson, A. L.: Effect of peak inert-mode temperature on elemental carbon measured using thermal-optical analysis, Aerosol Sci. Technol., 40, 763-780, 2006.

Sullivan, A. P., Weber. R. J., Clements, A. L., Turner, J. R., Bae, M. S., and Schauer, J. J.: A method for on-line measurement of water-soluble organic carbon in ambient aerosol particles: results from an urban site, Geophys. Res. Lett., 31, L13105, doi:10.1029/2004GL019681, 2004.

van Poppel, L. H., Friedrich, H., Spinsby, J., Chung, S. H., Seinfeld, J. H., and Buseck, P. R. Electron tomograohy of nanoparticle clusters: implications for atmospheric lifetimes and radiative forcing of soot, Geophys. Res. Lett., 32, L24811, doi:10.1029/2005GL024461, 2005.

Venkatachari, P., Zhou, L. M., Hopke, P. K., Schwab, J. J., Demerjian, K. L., Weimer, S., Hogrefe, O., Felton, D., and Rattigan, O.: An intercomparison of measurement methods for carbonaceous aerosol in the ambient air in New York City, Aerosol Sci. Technol., 40, 788-795, 2006.

Venkataraman, C., Habib, G., Eiguren-Fernandez, A., Miguel, A. H., and Friedlander, S. K.: 25 Residential biofuels in south Asia: carbonaceous aerosol emissions and climate impacts, Science, 307, 1454-1456, 2005.

Wang, Q., Shao, M., Zhang, Y., Wei, Y., Hu, M., and Guo, S.: Source apportionment of fine organic aerosols in Beijing, Atmos. Chem. Phys., 9, 8573-8585, 2009, http://www.atmos-chem-phys.net/9/8573/2009/.

so Wang, Z. H., Bai, Y. H., and Zhang S. Y.: A biogenic volatile organic compounds emission inventory for Beijing, Atmos. Environ., 37, 3771-3782, 2003.

Weingartner, E., Saathoff, H., Schnaiter, M., Streit, N., Bitnar, B., and Baltensperger, U.: Absorption of light by soot particles: determination of the absorption coefficient by means of

\section{Optical properties of elemental carbon and water-soluble organic carbon}

Y. Cheng et al.

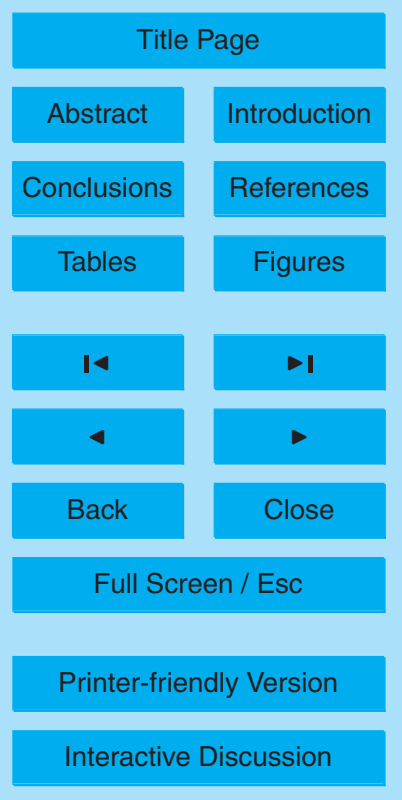


Aethalometers, J. Aerosol Sci., 34, 1445-1463, 2003.

Zhang, T., Claeys, M., Cachier, H., Dong, S. P., Wang, W., Maenhaut, W., and Liu, X. D.: Identification and estimation of the biomass burning contribution to Beijing aerosol using levoglucosan as a molecular marker, Atmos. Environ., 42, 7013-7021, 2008.

5 Zhang, X., Hecobian, A., Zheng, M., Frank, N. H., and Weber, R. J.: Biomass burning impact on $\mathrm{PM}_{2.5}$ over the southeastern US during 2007: integrating chemically speciated FRM filter measurements, MODIS fire counts and PMF analysis, Atmos. Chem. Phys., 10, 6839-6853, doi:10.5194/acp-10-6839-2010, 2010.

\section{ACPD}

$11,6221-6258,2011$

\section{Optical properties of} elemental carbon and water-soluble organic carbon

Y. Cheng et al.

Title Page

\section{Abstract}

Conclusions

Tables

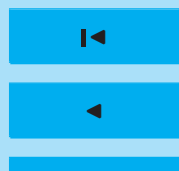

Back

\section{Introduction}

References
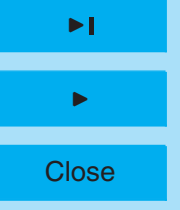

Full Screen / Esc

Printer-friendly Version

Interactive Discussion 


\section{ACPD}

$11,6221-6258,2011$

Table 1. Previously published mass absorption cross-section (MAC, in $\mathrm{m}^{2} \mathrm{~g}^{-1}$ ) of elemental carbon (EC). The lower and upper estimates of the "equivalent MAC", which is the estimated value if using the same measurement methods as used in this study, are also shown.

\begin{tabular}{|c|c|c|c|c|c|c|c|}
\hline \multirow[t]{2}{*}{ Sampling site } & \multirow[t]{2}{*}{ Sample description } & \multirow[t]{2}{*}{ Methods of $b_{\mathrm{abs}}^{\mathrm{a}}$} & \multirow[t]{2}{*}{ Methods of EC } & \multirow[t]{2}{*}{ Reported MAC } & \multicolumn{2}{|c|}{ Equivalent MAC } & \multirow[t]{2}{*}{ Reference } \\
\hline & & & & & Lower & Upper & \\
\hline \multicolumn{8}{|l|}{ Group 1} \\
\hline Philadelphia, PA & Severe sulfate haze episodes & Aethalometer $(880 \mathrm{~nm})$ & $\mathrm{NIOSH}(\mathrm{TOT})^{\mathrm{b}}$ & 59.9 & 55.6 & 69.5 & Jeong et al. (2004) \\
\hline New York & Urban, April to September & Aethalometer $(880 \mathrm{~nm})$ & NIOSH (TOT) & 33.2 & 30.8 & 38.5 & Rattigan et al. (2010) \\
\hline Chicago, IL & Urban, autumn & Aethalometer $(880 \mathrm{~nm})$ & IMPROVE (TOR) & 14.4 & 26.1 & 36.2 & Babich et al. (2000) \\
\hline Phoenix, AZ & Urban, winter & Aethalometer $(880 \mathrm{~nm})$ & IMPROVE (TOR) & 13.5 & 24.4 & 33.8 & Babich et al. (2000) \\
\hline Beijing, China & Urban, summer & DRI analyzer (632 nm) & IMPROVE-A (TOT) $)^{d}$ & 32.0 & & & This study \\
\hline Philadelphia, PA & Urban, summer & Aethalometer $(880 \mathrm{~nm})$ & IMPROVE (TOR) & 11.8 & 21.3 & 29.5 & Babich et al. (2000) \\
\hline Beijing, China & Urban, winter & DRI analyzer $(632 \mathrm{~nm})$ & IMPROVE-A (TOT) & 29.0 & & & This study \\
\hline New York & Urban, October to March & Aethalometer $(880 \mathrm{~nm})$ & $\mathrm{NIOSH}$ (TOT) & 23.2 & 21.6 & 27.0 & Rattigan et al. (2010) \\
\hline \multicolumn{8}{|l|}{ Group 2} \\
\hline Scotland, UK & Rural, June to December & Aethalometer $(880 \mathrm{~nm})$ & NIOSH (TOT) & 22.1 & 20.5 & 25.6 & Quincey et al. (2009) \\
\hline Atlanta, GA & Urban, summer & Aethalometer $(880 \mathrm{~nm})$ & NIOSH (TOT) & 20.4 & 19.0 & 23.7 & Lim et al. (2003) \\
\hline Palmerston, Canada & Urban, summer & Aethalometer $(880 \mathrm{~nm})$ & MSC (TOT) & 7.5 & $14.8^{\dagger}$ & $20.5^{\dagger}$ & Sharma et al. (2002) \\
\hline
\end{tabular}

Optical properties of elemental carbon and water-soluble organic carbon

Y. Cheng et al.

Title Page

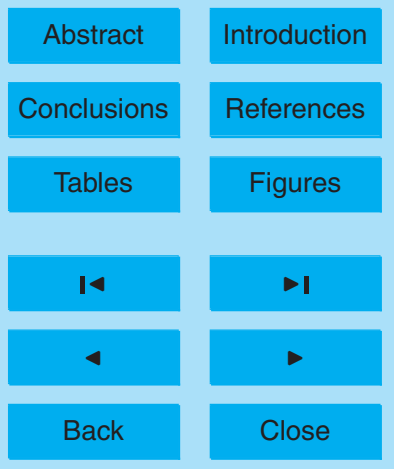

Full Screen / Esc

Printer-friendly Version

Interactive Discussion 


\section{ACPD}

$11,6221-6258,2011$

\section{Optical properties of elemental carbon and \\ water-soluble organic carbon}

Table 1. Continued.

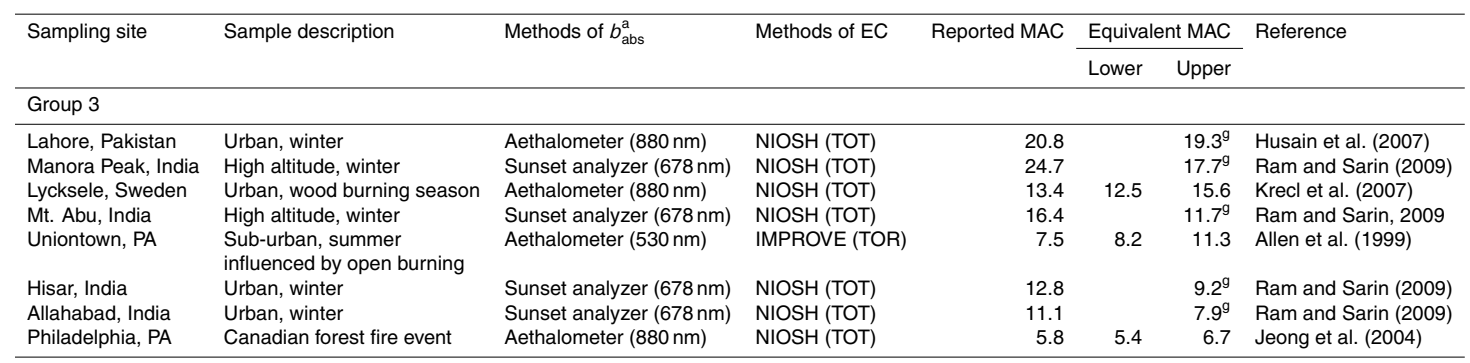

a The operating-wavelength shown in parentheses.

${ }^{b} \mathrm{NIOSH}$ temperature protocol with transmittance correction.

${ }^{\mathrm{c}}$ IMPROVE temperature protocol with reflectance correction.

d IMPROVE-A temperature protocol with transmittance correction.

${ }^{e}$ MSC (Meteorological Service of Canada) temperature protocol with transmittance correction.

${ }^{f}$ EC determined by the MSC method was 1.09 times the value of that determined by the IMPROVE temperature protocol with reflectance correction (Sharma et al., 2002). In Eq. (10), $f_{\text {charring }}=(1.3 \sim 1.8) \times 1.09, f_{\text {protocol }}=1$.

g The upper estimate of "equivalent MAC" calculated by a $f_{\text {protocol }}$ value of 1.5 .

Y. Cheng et al.

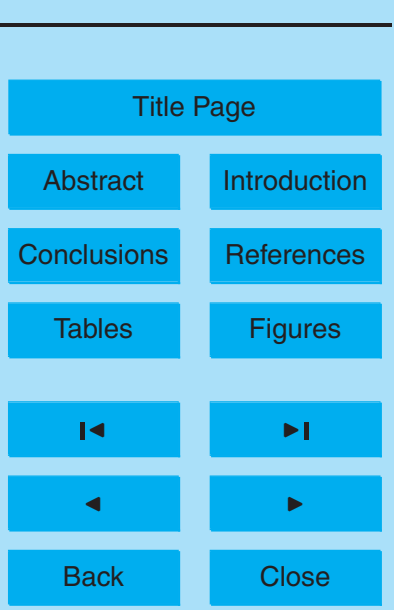

Full Screen / Esc

Printer-friendly Version

Interactive Discussion 


\section{ACPD}

$11,6221-6258,2011$

\section{Optical properties of} elemental carbon and water-soluble organic carbon

Table 2. Ratios of reflectance-defined $E C\left(E C_{R}\right)$ to transmittance-defined $E C\left(E C_{T}\right)$.

\begin{tabular}{lllrl}
\hline Protocol & Sampling site & Sample description & Ratio & Reference \\
\hline IMPROVE & Multiple, US & Urban, sub-urban, and rural & 1.78 & Chow et al. (2001) \\
IMPROVE & Multiple, Mexico & Urban & 1.47 & Chow et al. (2001) \\
IMPROVE & Fresno, CA & Aug 2002-Apr 2003; urban & 1.49 & Chow et al. (2004) \\
IMPROVE & Fresno, CA & Aug-Sep 2005; urban & 1.33 & Chow et al. (2009) \\
IMPROVE-A & Beijing, China & Winter and summer, 2009; urban & 1.78 & Cheng et al. (2010) \\
IMPROVE & - & Motor vehicle exhaust; source & 1.21 & Chow et al. (2001) \\
\hline NIOSH & Multiple, Mexico & Urban & 1.00 & Chow et al. (2001) \\
STN & Fresno, CA & Aug 2002-Apr 2003; urban & 3.45 & Chow et al. (2004) \\
STN & Hong Kong, China & Nov 2000-Oct 2001; urban & 1.16 & Chow et al. (2005) \\
\hline
\end{tabular}

Y. Cheng et al.

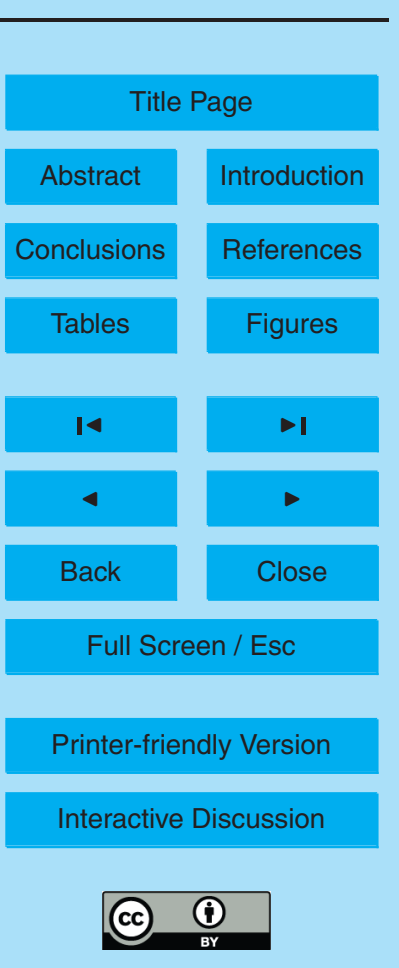




\section{ACPD}

$11,6221-6258,2011$

\section{Optical properties of} elemental carbon and water-soluble organic carbon

Table 3. Lower and upper estimates of the "equivalent MAC" values before and after correction for the artifacts associated with the "filter-based" method (an enhancement factor of 1.87 was used).

\begin{tabular}{lrrrrl}
\hline & \multicolumn{2}{c}{$\begin{array}{c}\text { Equivalent MAC } \\
\text { uncorrected }\end{array}$} & \multicolumn{2}{c}{$\begin{array}{c}\text { Equivalent MAC } \\
\text { corrected }\end{array}$} & Note \\
\cline { 2 - 5 } & Lower & Upper & Lower & Upper & \\
\hline Group 1 & $21 \sim 31$ & $27 \sim 40$ & $11 \sim 17$ & $14 \sim 21$ & Significantly enhanced by coating \\
Group 2 & $15 \sim 21$ & $21 \sim 26$ & $8 \sim 11$ & $11 \sim 14$ & Moderately enhanced by coating \\
Group 3 & & $<20$ & & $<11$ & Impacted by biomass burning \\
\hline
\end{tabular}

Y. Cheng et al.

Title Page

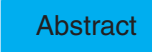

Introduction

Conclusions

References

Tables

Figures

14

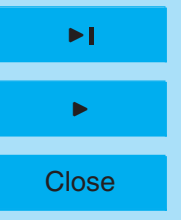

Back

Full Screen / Esc

Printer-friendly Version

Interactive Discussion 

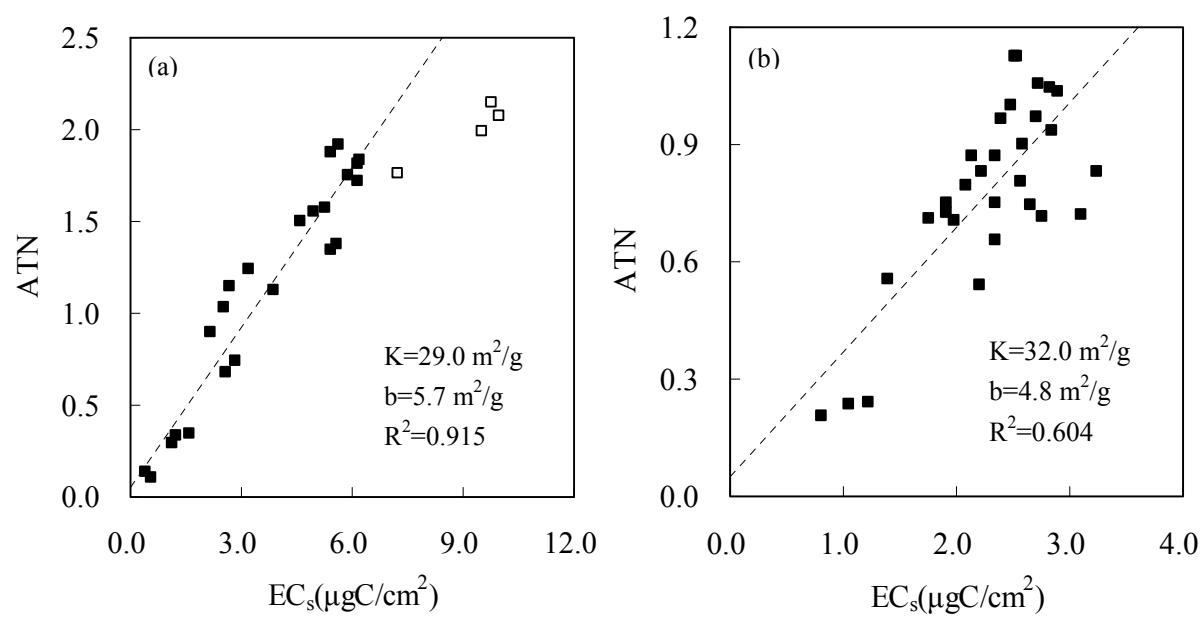

Optical properties of elemental carbon and water-soluble organic carbon

Y. Cheng et al.

Fig. 1. Comparison of light attenuation measured at $632 \mathrm{~nm}\left(\right.$ ATN) and $E C$ loading $\left(E C_{s}\right)$ during winter (a) and summer (b) respectively. Linear regression results are shown with $K$ as the slope and $b$ as the intercept. Data points with ECs exceeding $7 \mu \mathrm{gC} \mathrm{cm}^{-2}$, as shown by the open squares, were not included in the regression to avoid the shadowing effect.

Title Page

Abstract

Conclusions

Tables

14

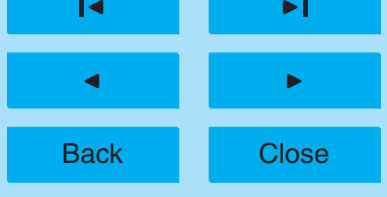

Full Screen / Esc

Printer-friendly Version 


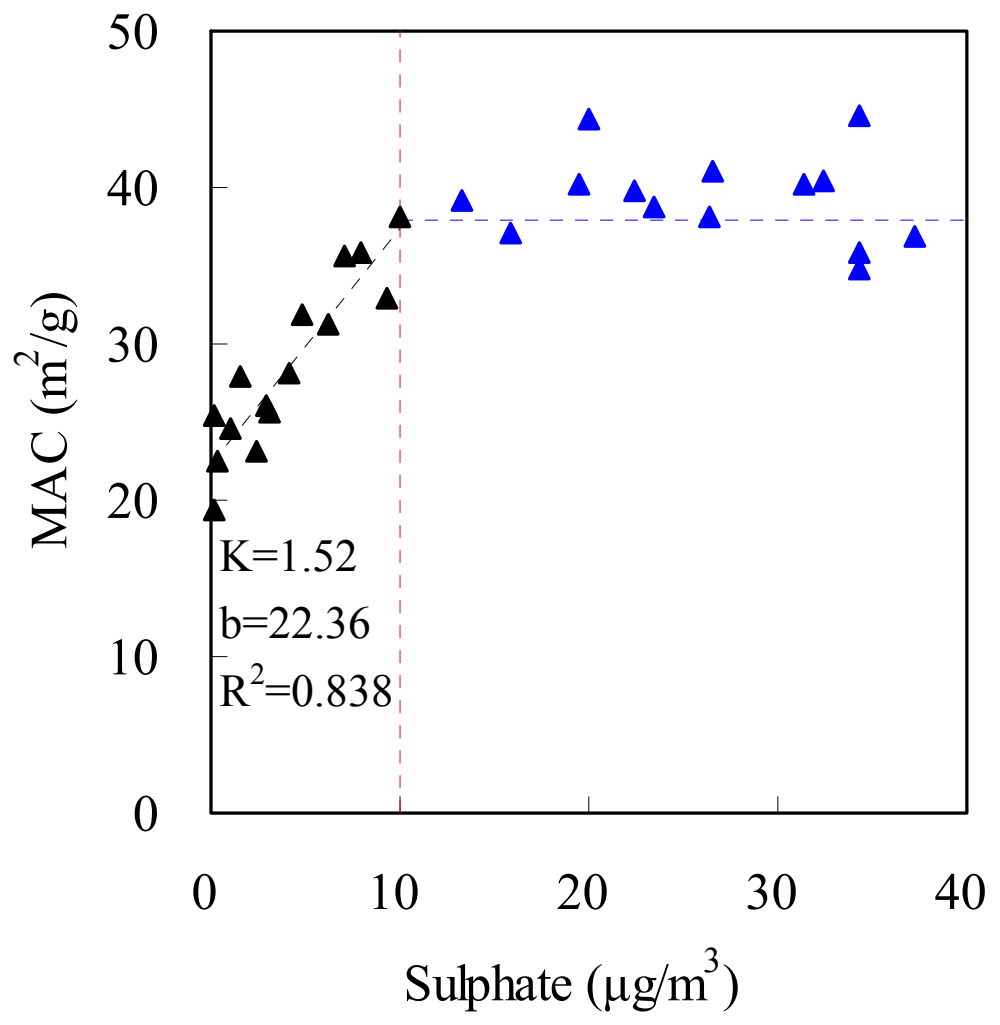

\section{ACPD}

$11,6221-6258,2011$

Optical properties of elemental carbon and water-soluble organic carbon

Y. Cheng et al.

Title Page

Abstract

Conclusions
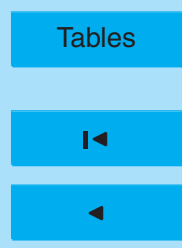

Back
Introduction

References

Figures

$>1$

$>$

Close

Fig. 2. Relationship between the $M A C$ of $E C$ and the sulphate concentration during summer. Linear regression results are shown with $K$ as the slope and $b$ as the intercept. The linearity did not extend for sulphate exceeding $10 \mathrm{\mu g} \mathrm{m}^{-3}$, as indicated by the red dash line. The trend was similar during winter.

\section{Full Screen / Esc}

Printer-friendly Version

Interactive Discussion 


\section{ACPD}

$11,6221-6258,2011$

\section{Optical properties of}
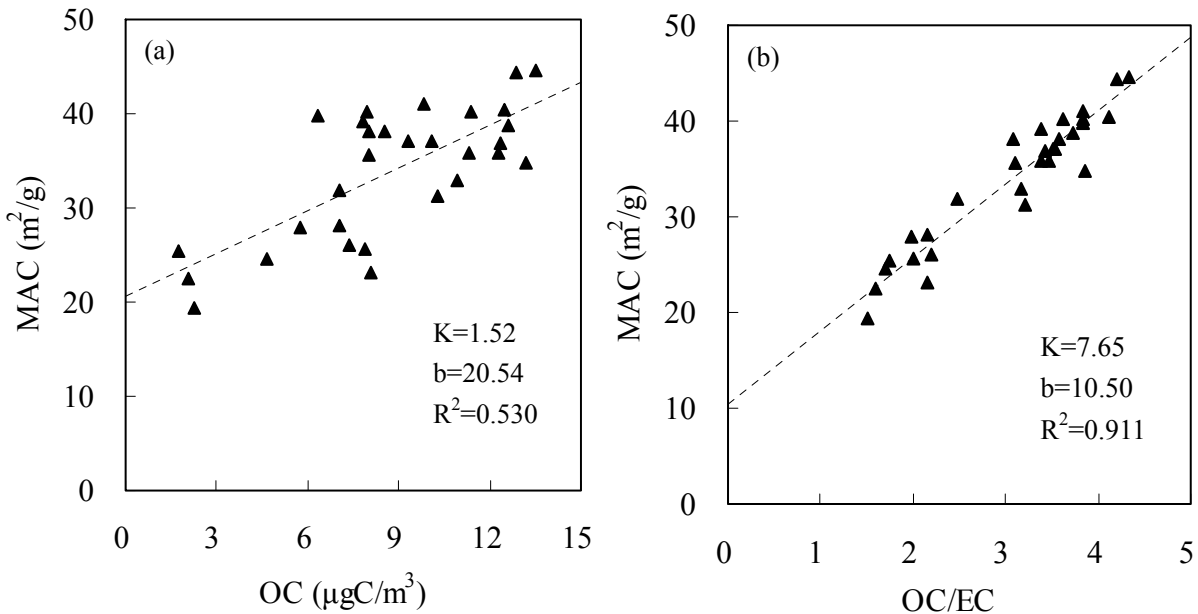

elemental carbon and

water-soluble organic carbon

Y. Cheng et al.

Fig. 3. Relationship between the MAC of EC and (a) the OC concentration, (b) the OC to EC ratio $(\mathrm{OC} / \mathrm{EC})$ during summer. Linear regression results are shown with $K$ as the slope and $b$ as the intercept. The trend was similar during winter.

Title Page

Abstract

Introduction

Conclusions

References

Tables

Figures

14

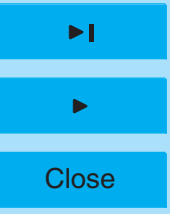

Full Screen / Esc

Printer-friendly Version

Interactive Discussion 


\section{ACPD}

$11,6221-6258,2011$

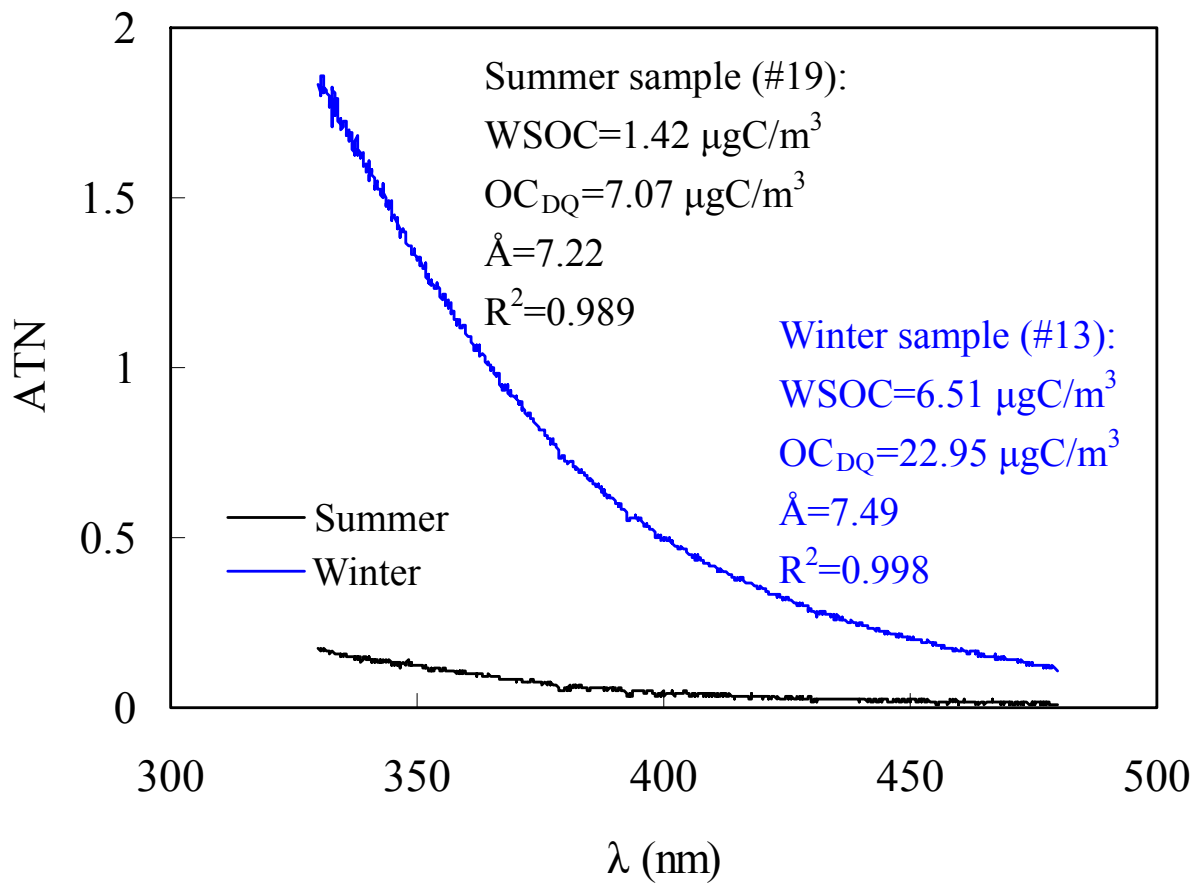

Optical properties of elemental carbon and water-soluble organic carbon

Y. Cheng et al.

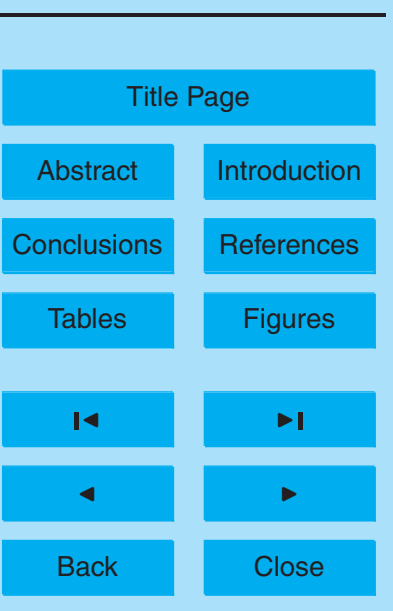

Full Screen / Esc

Fig. 4. Representative adsorption spectra of WSOC during winter and summer respectively.

Printer-friendly Version

Interactive Discussion 


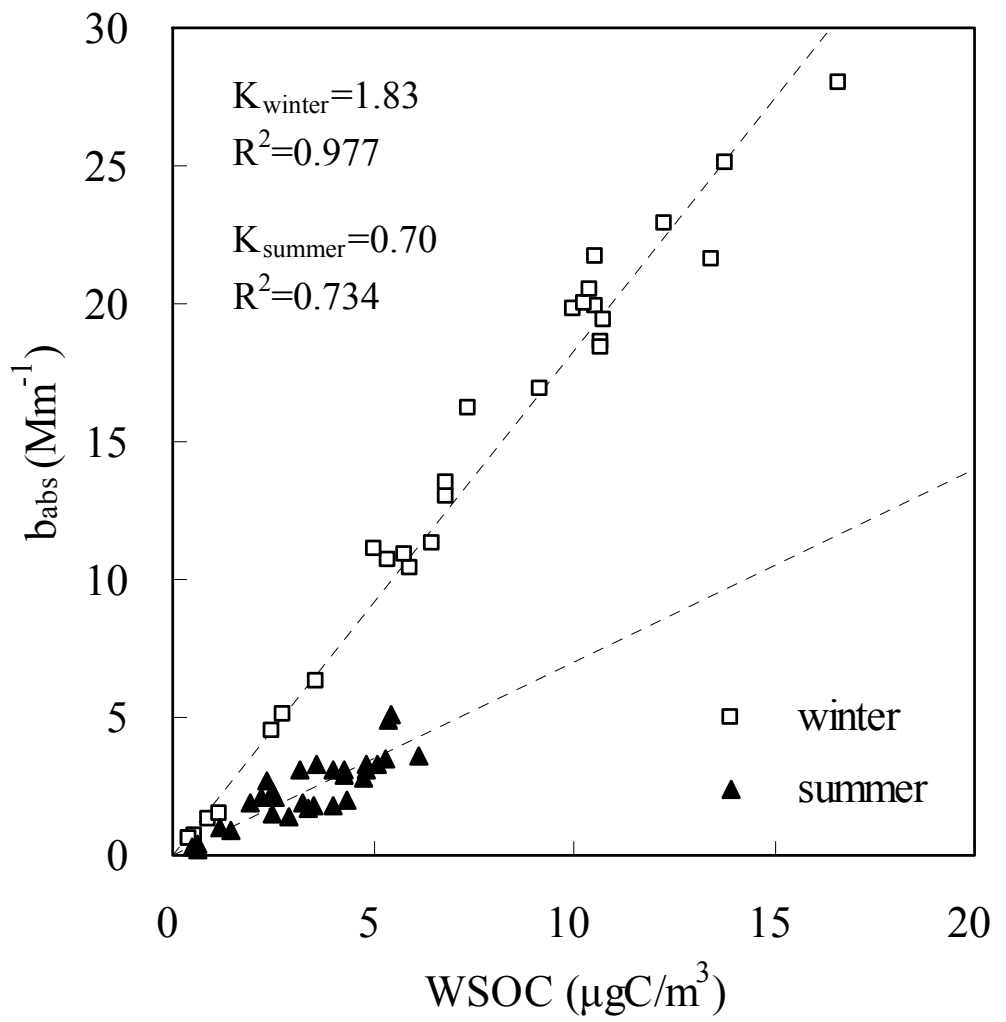

Fig. 5. Comparison of $b_{\mathrm{abs}}$ measured at $365 \mathrm{~nm}$ and the WSOC concentration during winter and summer. Linear regression results are shown with $K$ as the slope (intercept is set as zero).

\section{ACPD}

$11,6221-6258,2011$

Optical properties of elemental carbon and water-soluble organic carbon

Y. Cheng et al.

Title Page

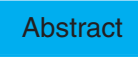

Introduction

Conclusions

References

Tables

Figures

14

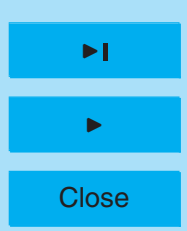

Back

Full Screen / Esc

Printer-friendly Version

Interactive Discussion 